\title{
BIM Compatibility and its Differentiation with Interoperability Challenges as an Innovation Factor
}

\author{
Sara Shirowzhan ${ }^{\mathrm{a}}$, Samad M.E. Sepasgozar ${ }^{\mathrm{b}}$, David J. Edwards ${ }^{\mathrm{c}}$, Heng Li ${ }^{\mathrm{d}}$, Chen Wang \\ ${ }^{a}$ Faculty of Built Environment, University of New South Wales, Sydney, Australia. Email: \\ s.shirowzhan@unsw.edu.au \\ ${ }^{\mathrm{b}}$ Faculty of Built Environment, University of New South Wales, Sydney, Australia. Email: \\ Samad.sepasgozar@gmail.com \\ ${ }^{\mathrm{c} S c h o o l}$ of Engineering and the Built Environment, Birmingham City University, UK and \\ University of Johannesburg, South Africa. Email: drdavidedwards@aol.com \\ ${ }^{\mathrm{d}}$ Faculty of Construction and Environment, Hong Kong Polytechnic University, Hong Kong. \\ Email: heng.li@.polyu.edu.hk \\ ${ }^{\mathrm{e}}$ College of Civil Engineering, Huaqiao University, 361021 Xiamen, China, and Fujian \\ Province Higher-Educational Engineering Research Centre, 361021 Xiamen, China. Email: \\ derekisleon@gmail.com
}

Corresponding Author: Dr. Samad Sepasgozar. Corresponding Email:

Samad.sepasgozar@gmail.com

\begin{abstract}
Building information modelling (BIM) applications are being increasingly introduced throughout the construction industry and within academia, a large amount of BIM applications has been recommended within literature. However, coverage of the theory of BIM diffusion (which combines contextual and technical issues of the applications) remains scant and underdeveloped. Compatibility is one of the key contextual factors of Diffusion of Innovation theory that involves predicting BIM adopters' behaviours and identifying what components require extra effort for successful BIM implementation. However, this important theoretical concept has not been developed in pertinent BIM literature nor used correctly to extend existing knowledge because compatibility variables are not understood in a construction context. This seriously impedes the correct usage of BIM in construction. This study systematically and critically reviews BIM compatibility (BIM-COM) literature to distinguish compatibility issues at the organisational level and the concept of interoperability at the technical level. A sample of 57 out of the 131 articles constituted secondary data and each paper represented the unit of analysis. Bibliographic analysis techniques were used to identify co-authoring network and contents' concentration in the created bibliography. Content analysis and text mining approaches were employed using a thematic clustering analysis for grouping authors and themes within articles. The findings illustrate that the concept of compatibility is surprisingly poorly understood and often overlooked in the literature. The paper argues that interoperability issues prevail as the key practical barrier to BIM implementation. The paper identifies a large knowledge gap in terms of improving compatibility measures, which should be employed by innovators to assess their BIM applications before they offer it to construction companies. The findings presented will help to extend BIM applications and speed up the adoption rate among stakeholders with different needs and using different file formats.
\end{abstract}

Keywords: Compatibility, interoperability, adoption, implementation, data and model exchange, BIM. 


\section{Introduction}

Whilst the concept of BIM became common parlance within construction literature prior to 2000, efficient implementation of BIM (and at full capacity) in companies at different levels within various countries remains a challenge. In the 1980s, Rogers [1] introduced Diffusion of Innovation (DOI), which investigates how an innovation is communicated and diffused over time through a social system [2,3]. The theory comprises two main components: the cumulative number of adopters; and time. Diffusion is viewed as a 'passive' process whereby the relative advantages of new technology are communicated between industry members through the process of socialization [4-6]. Diffusion studies predominantly focus upon the adopter organizations in a certain sector and the communication channels they use to increase the awareness of a new technology (e.g. word-of-mouth or media). Sepasgozar et al. [7] discuss how innovation is communicated based upon a social mechanism relying on the adopter community, and the dissemination process relying on the managed mechanism and innovator strategies to interact with users. However, Rogers also suggests five characteristics for DOI, namely: (i) relative advantage; (ii) compatibility; (iii) complexity; (iv) trialability; and (v) observability. For almost two decades, the 'relative advantages' of BIM espoused within literature have encouraged industry adoption, where these palpable advantages include: lean architectural practice [8]; facility management [9]; and cost control [10]. Previous studies also discuss the 'complexity' of BIM as an innovation characteristic [11-13] and attempt to develop more applications to alleviate complexity issues [14,15]. Similarly, the 'trialability' and 'observability' characteristics of DOI have been examined in different countries such as Pakistan [16], Malaysia [17] and Nigeria [18]. Of the five characteristics, 'compatibility' (i.e. with user needs, values and experience) has received a significant dearth of academic attention. For example, while Abanda et al. [32] review different software packages used for BIM within construction projects the research does not discuss compatibility and interoperability from the BIM adoption perspective.

Whilst compatibility is a vital measure for predicting or facilitating BIM adoption within a specific context [19], it has yet to be examined in this context because it is not fully understood. Compatibility measures for extending a technology are perceived as consistent with the needs, values and competencies of potential adopters at either organisational or user level [98]. At present, the literature has either not used compatibility correctly for measurement of BIM users' values at the organisation level, or it has ignored compatibility completely. Previous studies investigate interoperability of BIM with other systems, but as systems advance the interoperability is a continuously challenging issue in the field. Anecdotal evidence suggests that literature distinguishes different values or needs depending on the context, such as for large companies or small-sized companies [20,21]. Other technical studies report upon the experience and observed challenges of users in practice. However, compatibility is rarely examined as an independent factor and neither are its variables identified in a construction technology context. For example, Venkatesh (UTAT) identifies image, job relevance, output quality and result as four main variables of 'perceived usefulness', which is the main construct of the technology acceptance model (Davis 1983). BIM uptake therefore remains slow, much to the frustration of industry and government policy makers. Scholars from different disciplines report that some reasons for the slow adoption rate of information systems such as BIM and graphic information systems (GIS) are associated to compatibility $[22,23]$ and also interoperability with software packages required for different tasks [24]. At a technical level, interoperability refers to the ability of a technology to exchange information, communicate and cooperate with other systems without major modification of their structure. Consequently, the technology can work with a user's 
existing technologies, despite differences in the implementation language, resulting in a collective behaviour [25]. For example, Zuluaga and Albert [22] investigate bridge case studies in North California and reveal that the Department of Transportation has adopted some fall protection supplementary devices that are not compatible with bridge guardrails. Thus, they suggest that compatibility should be assessed before a fall protection system is procured.

To preserve consistency and develop uniformity throughout the paper, technology-related terms are defined here. 'Technology' refers to a broad concept comprising artefacts, knowledge about them and the practices pertaining to their operation and maintenance [2628]. Technology also refers to user-embodied knowhow, expertise and associated processes [28]. In a construction context, 'technology' refers to any tools or machines and/or their modifications that are used to carry out a construction task, achieve the project objectives, manage and monitor construction operation, perform a specific function or solve a problem [26,29,30]. Most specifically, 'construction technology' embraces tools, systems, mechanisms, computers, electronic boards and components, equipment and any combination of resources used for carrying out physical construction activities in the process of construction from design to demolition. This definition of technology embraces BIM as a process by which to model, analyse, simulate, integrate and visualize building information by using different software and hardware devices and a computer-intelligible exchange method of building information that contributes to the delivery of a construction project [31-33]. The literature illustrates a shift from manually-operated systems and equipment to automated systems or to 'machine-dominated' construction operations [26], by exploring and demonstrating the relative advantages of the technology. A wide range of technologies which need to be integrated with BIM do receive attention in the literature, [34-36], such as virtual reality (VR) and augmented reality (AR) [37,38]; mobile and wearable technologies [39]; Lidar [40-42]; automated material identification [43]; real-time location and tracking systems [44]; and GPS-guided plant and machinery [45].

The process of adopting these technologies (including BIM adoption) is also discussed frequently. Construction technology adoption theories [7] are founded upon the established body of knowledge of information systems $[1,46]$. 'Technology acceptance' is nested in the psychological theories that predict individual decision and intention to use a new technology pertinent to a series of mental and behavioural states [47]. At the organisational level, where the decision is made through a formal process, and more than one person is involved in the decision-making, the 'technology adoption' process from a managerial perspective should be investigated $[7,48]$. User acceptance can be one of the critical determinants of the adoption process in an organisation. However, the ambiguities regarding compatibility as a key possible factor in BIM adoption have stifled the development of a clear understanding of the adoption process. This has resulted in inaccurate prediction of BIM implementation, and a low rate of BIM adoption [49-51,21,52,53]. At present, the digital technology market does not provide a task-specific solution for compatibility and its associated technical concept of interoperability, which negatively affects the demand pull and technology push [54]. Compatibility measures how BIM is perceived to be consistent with a user's experience, needs and values. As the construction industry is a fragmented industry with multiple stakeholders each having different values and needs, and using different software platforms, compatibility (at both organisational and technical levels) must be carefully investigated [53]. Wang and Dunston [55] consider compatibility as a factor of ergonomic property. They assume that compatibility is addressed where the virtual reality user correctly interprets representations of virtual and real objects. From this perspective, the compatibility effects 
arising from the differences in the format of information derive from virtual and real objects, and also affect the user's interpretation of the object. This makes the process of data and model exchange time consuming and sometimes impossible. However, this is the common definition in the literature and can be a confusion where a scholar investigates compatibility of a new technology.

Whilst ubiquitous literature sources endorse BIM in different contexts and promote it as a multi-actor and multi-discipline collaborative system [56], BIM project fit and compatibility, and also its quality in terms of interoperability across stakeholders' applications, have not been fully examined in different complicated cases. Some of the associated measures of technical compatibility are discussed in information systems such as fault tolerance $[57,58]$, interoperability, user error protection, reusability or maintainability and portability. Recent studies report large gaps in BIM implementation [59] with serious challenges for the integration of BIM with other emerging technologies such as Internet of Things (IoT), sensors and cloud computing [60] and Cloud [56]. While the value of interoperability of BIM has been extensively discussed, the main issue has been its interoperability with AutoCAD files [61] and recently energy software. This need has shifted from 2D drawings to a variety of aforementioned emerging technologies [56]. BIM represents a shared knowledge system (containing geometric and semantic information) about a building [32,62] or a collaborative system [56], although this paper discusses the technical challenges of sharing information and delivering or transferring data to stakeholders' systems. Other BIM concepts used in the literature include virtual design and construction (VDC) [32,63] and multi-dimensional models, such as time as a fourth dimension (4D) [32,64-66], cost as a fifth dimension (5D) $[67,56,68]$, life cycle analysis as a sixth dimension (6D) [34], facility management application as a seventh dimension (7D) and building occupancy as an eight dimension (8D). Previous studies suggest that compatibility with the existing infrastructure of a potential adopter and their current practices or processes are major requirements for successful BIM adoption [69-71,54]. However, this concept has not been used correctly but rather as a general term in various BIM implementation efforts. According to Rogers, compatibility can be defined as the degree that the technology is consistent with the user's experience, needs and values, and the current infrastructure in a construction company.

This paper aims to identify BIM compatibility (BIM-COM) articles and systematically analyse them (as a secondary data source and unit of analysis) to determine prevailing gaps in knowledge. A concomitant objective is to identify how the concepts of compatibility at the organisational level, and interoperability at the technical user level, have developed within construction literature and importantly, how this development informs practice. A deeper understanding of compatibility for vendors and application developers to involve in DOI is developed by offering a technology more compatible to construction companies' values and needs. The research argues that the literature is fragmented and ignores the classical concepts and theories of technology adoption and implementation in information systems. For example, the concept of adoption and implementation are used interchangeably without careful consideration of their relevant theoretical backgrounds. This review first develops a systematic search method to identify relevant articles and develop the BIM-COM data base. Second, the results of bibliographic analysis are presented and third, the results of content analysis are reviewed, including the main themes covered in the literature. Finally, there is a discussion of the knowledge gap and opportunities for future studies. 


\section{Review methods}

The overarching methodological position employed for this current study was interpretivist epistemological design that utilised extant literature as an invaluable secondary source of data, where each paper constituted a unit of analysis. From an operational perspective, a fourstage waterfall process was adopted to conduct the systematic review of literature, namely: (i) database selection; (ii) primary search with controlled criteria; (iii) bibliography analysis; and (iv) content analysis. The first two steps sought to identify and develop the BIM-COM literature database. The last two steps constituted the analytical phase.

\subsection{Step 1: Database selection}

Relevant publications to the BIM-COM topic were chosen from the Scopus database of journal publications (https://www.scopus.com/sources). Bibliographic analysis was used to methodically identify patterns of co-authorship and co-occurrence of keywords. The textual string utilised included two main search terms of 'building information modelling' and 'compatibility' and resulted in 131 articles being identified as relevant to the current study.

\subsection{Step 2: Filtering and controlled criteria}

Further cleansing and filtering of the sample was required to ensure that only relevant articles were included in the ensuing analysis. Specific criteria (including paper type, language, year and journal) were applied to filter the search results and find recent papers relevant to compatibility. Viz: ( ALL ("building information model*" ) AND ALL ("compatibility")) AND ( EXCLUDE ( DOCTYPE, "cp" ) ) AND ( EXCLUDE ( LANGUAGE , "German" ) OR EXCLUDE ( LANGUAGE, "Chinese" ) OR EXCLUDE ( LANGUAGE , "Lithuanian" ) OR EXCLUDE ( LANGUAGE, "Portuguese" ) ) AND ( EXCLUDE ( SRCTYPE, "p" ) OR EXCLUDE ( SRCTYPE, "b" ) OR EXCLUDE ( SRCTYPE, "k" ) OR EXCLUDE ( SRCTYPE, "d" ) ). This resulted in a total of 57 full papers that constituted the pertinent BIM-COM literature. The cluster and content analysis created thematic clusters of articles with similarities in reference keywords. Systematically reviewing each cluster sought to identify gaps, deficiencies or directions in the literature based on the BIM-COM database articles.

\subsection{Steps 3 and 4: Bibliography and content analysis}

The co-occurrence analytical map of keywords was created using bibliographic analysis of the literature to understand the main keywords and topics used in the sample BIM-COM. Furthermore, the co-authorship network, using the full counting method, was also undertaken to show authors who have contributed to the BIM-COM literature. Since these types of analyses do not provide an in-depth insight into the literature, content analysis was also carried out. All papers were clustered by their similarity using Jaccard's coefficient as a similarity metric. Five clusters are shown in Figure 1. The content of the articles in each cluster was carefully reviewed and analysed. 


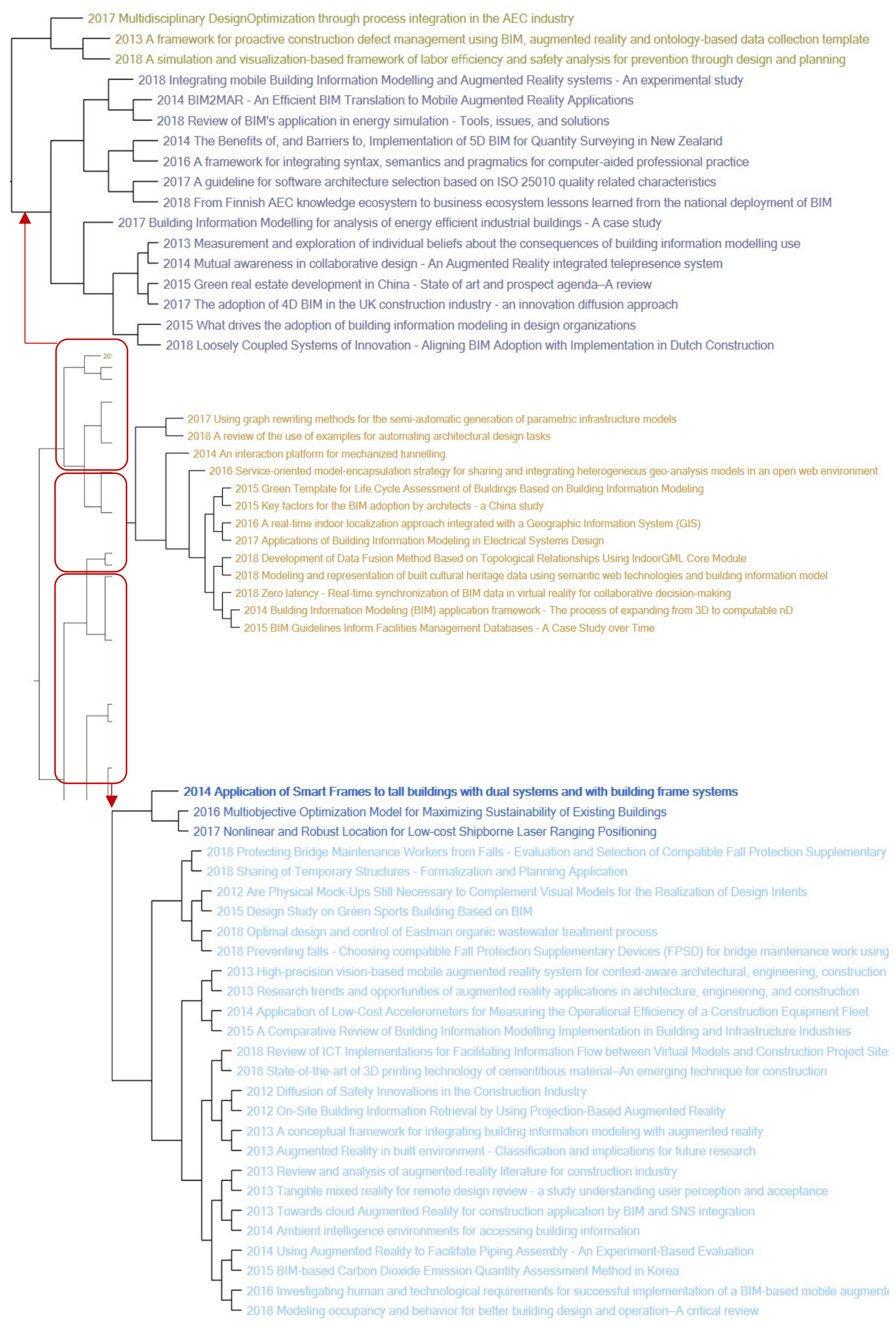

Figure 1. Five clusters of the sample BIM-COM dataset. 


\section{Results}

244 Figure 2 illustrates a co-occurrence analytical map of keywords created using the bibliographic BIM-COM database of research articles. The size of the nodes is indicative of the volume of publications that include these keywords - hence the larger the node, the greater the body of knowledge in that area. The BIM-COM literature shows that the main focus of adoption and implementation is larger for architectural companies than the construction industry.

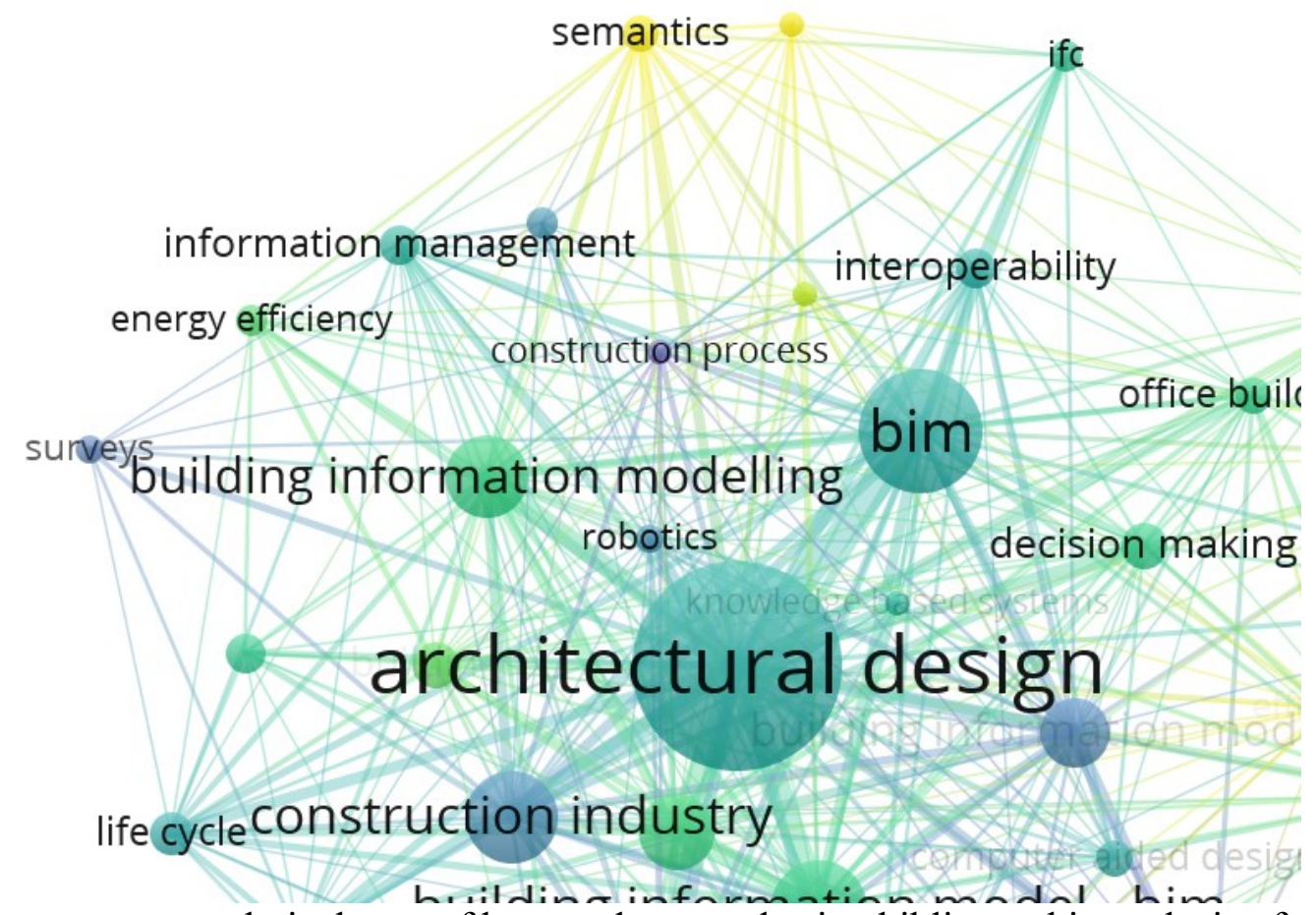

Figure 2. Co-occurrence analytical map of keywords created using bibliographic analysis of the literature.

Note: The minimum number of co-occurrences of keywords was 5. The network includes 1269 keywords identified in the developed bibliography.

Figure 3 illustrates the co-authorship networks created using the full counting method, which considers a full weight of ' 1 ' for each co-author for each identified paper. Thus, the total weight of the article will be equal to the number of authors of that article [72]. Each circle in the figure represents an author and its diameter reflects the number of publications of the corresponding author indexed in Scopus. The approximate strength of the co-authorship link between corresponding authors is represented by the distance between two circles. Lines are used to indicate the strongest co-author links and hence, the shorter lines illustrate a stronger co-authorship link between the authors on this topic. Colours such as green or red represent clusters of ${ }^{n}$ authors with strong co-authorship links. Figure 3(a) shows that there are 330 coauthors involved in the literature with a minimum number of 1 . This clearly demonstrates that there are many sets of co-authors who are not connected to each other and possibly work on different sub-domains within the literature. Figure 3(b) shows the largest co-authorship network with 34 co-authors and reveals fairly small networking between the authors of the selected literature. 


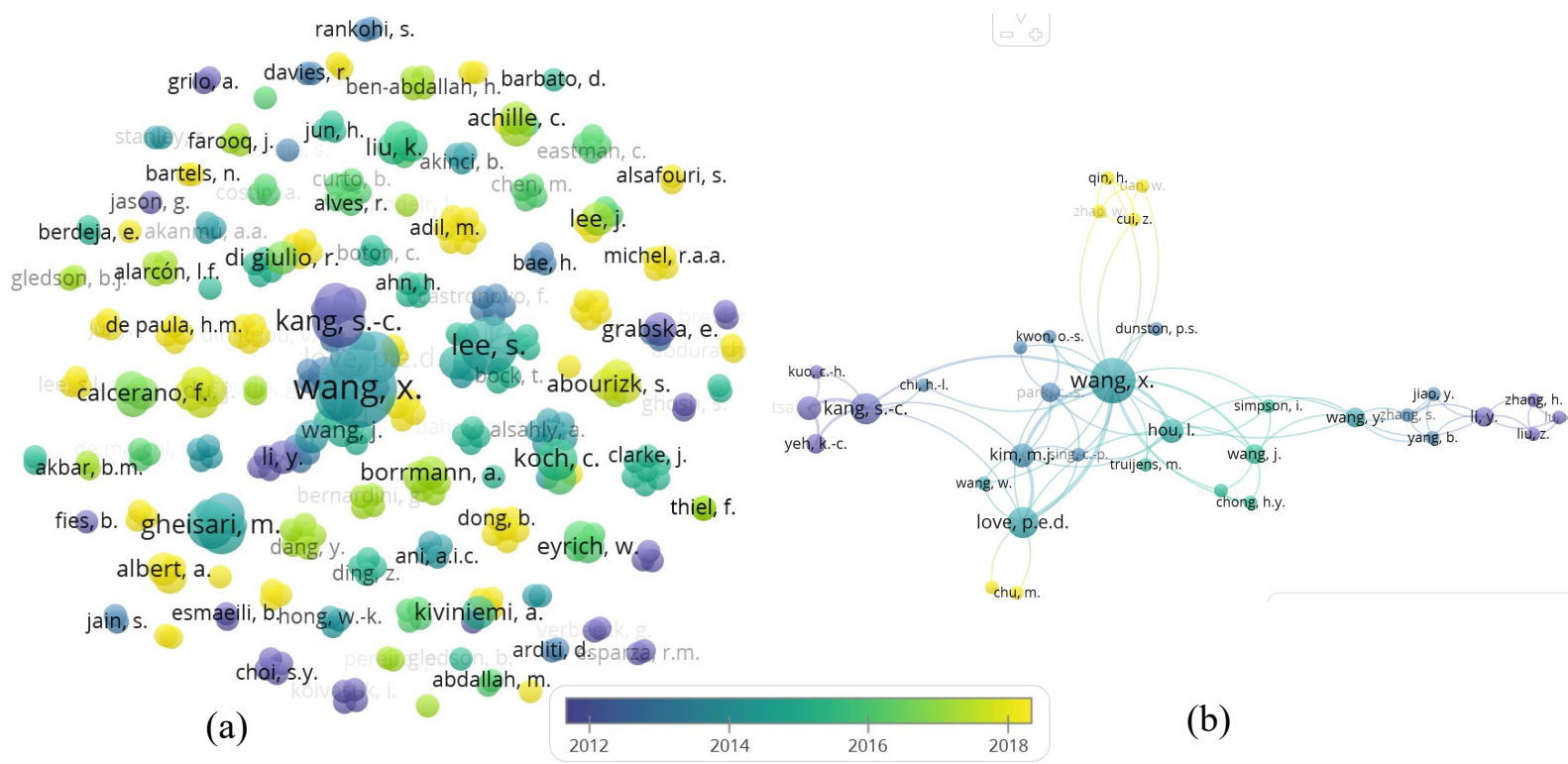

Figure 3. Visualisation of the co-authorship network using the full counting method. (a) the network for all 330 co-authors, and visualisation (b) the largest network within the literature. Note: The minimum number of articles by an author was considered as 1 .

In order to gain insight into the papers and key target journals, all papers of the BIM-COM literature were ranked against their citations. Table 1 shows that papers discussing the interoperability of BIM with other technologies (such as AR and VR) received more citations over time or per year. Most of the top high-cited papers were published in Automation in Construction.

Table 1. Selected high-cited articles in the BIM-COM literature based on Scopus data set in 2019.

\begin{tabular}{|c|c|l|l|c|c|}
\hline ID & Year & Topic and reference details & Journal & Citation & $\begin{array}{c}\text { Citation } \\
\text { per year }\end{array}$ \\
\hline 54 & 2013 & BIM and AR for defect management [73] & Automation in Construction & 100 & 17 \\
\hline 55 & 2013 & $\begin{array}{l}\text { Research trends of AR applications in } \\
\text { architecture and construction [74] }\end{array}$ & Automation in Construction & 97 & 16 \\
\hline 45 & 2014 & $\begin{array}{l}\text { BIM applications and expanding from 3D to } \\
\text { computable nD [32] }\end{array}$ & Automation in Construction & 80 & 16 \\
\hline 56 & 2013 & Future research of AR in built environment [75] & Automation in Construction & 73 & 12 \\
\hline 57 & 2013 & Integration of BIM and VR [76] & Automation in Construction & 69 & 12 \\
\hline 32 & 2015 & $\begin{array}{l}\text { Review of BIM in building and infrastructure } \\
\text { industries [77] }\end{array}$ & $\begin{array}{l}\text { Archives of Computational Methods } \\
\text { in Engineering }\end{array}$ & 44 & 11 \\
\hline 33 & 2015 & $\begin{array}{l}\text { Adoption of BIM in design organizations } \\
\text { considering architects' behavioural intentions }\end{array}$ & Automation in Construction & 44 & 11 \\
\hline 64 & 2012 & Review the IFC standard [78] & $\begin{array}{l}\text { Electronic Journal of Information } \\
\text { Technology in Construction }\end{array}$ & 70 & 10 \\
\hline 19 & 2017 & BIM for energy efficiency analysis [53] & $\begin{array}{l}\text { Renewable and Sustainable Energy } \\
\text { Reviews }\end{array}$ & 19 & 10 \\
\hline 58 & 2013 & $\begin{array}{l}\text { Vision-based mobile AR system for facility } \\
\text { management applications [79] }\end{array}$ & Visualization in Engineering & 47 & 8 \\
\hline 34 & 2015 & Review of green real estate development [80] & $\begin{array}{l}\text { Renewable and Sustainable Energy } \\
\text { Reviews }\end{array}$ & 28 & 7 \\
\hline 59 & 2013 & Cloud AR and integration with BIM and SNS & Automation in Construction & 40 & 7 \\
\hline
\end{tabular}




\begin{tabular}{|c|c|c|c|c|c|}
\hline & & [81] & & & \\
\hline 60 & 2013 & Individual beliefs and BIM [69] & $\begin{array}{l}\text { Construction Management and } \\
\text { Economics }\end{array}$ & 38 & 6 \\
\hline 35 & 2015 & BIM adoption by architects [82] & $\begin{array}{l}\text { Engineering, Construction and } \\
\text { Architectural Management }\end{array}$ & 25 & 6 \\
\hline 46 & 2014 & $\begin{array}{l}\text { Mutual awareness in collaborative design using } \\
\text { AR [83] }\end{array}$ & Computers in Industry & 30 & 6 \\
\hline 47 & 2014 & $\begin{array}{l}\text { Intelligence BIM for healthcare facility } \\
\text { management }[84]\end{array}$ & Facilities & 25 & 5 \\
\hline 48 & 2014 & $\begin{array}{l}\text { 5D BIM implementation for quantity surveying } \\
\text { in New Zealand [68] }\end{array}$ & $\begin{array}{l}\text { Australasian Journal of Construction } \\
\text { Economics and Building }\end{array}$ & 24 & 5 \\
\hline 36 & 2015 & BIM and facilities management databases [63] & Buildings & 19 & 5 \\
\hline 37 & 2015 & $\begin{array}{l}\text { Green template for life cycle assessment using } \\
\text { BIM [85] }\end{array}$ & Sustainability (Switzerland) & 19 & 5 \\
\hline 38 & 2015 & AR for facilitating piping assembly [86] & $\begin{array}{l}\text { Journal of Computing in Civil } \\
\text { Engineering }\end{array}$ & 19 & 5 \\
\hline 65 & 2012 & On-site BIM retrieval by using AR [87] & $\begin{array}{l}\text { Journal of Computing in Civil } \\
\text { Engineering }\end{array}$ & 33 & 5 \\
\hline 61 & 2013 & Review of AR literature [88] & Visualization in Engineering & 28 & 5 \\
\hline 26 & 2016 & $\begin{array}{l}\text { Integrating geo-analysis models in an open web } \\
\text { environment [89] }\end{array}$ & $\begin{array}{l}\text { ISPRS Journal of Photogrammetry } \\
\text { and Remote Sensing }\end{array}$ & 14 & 5 \\
\hline 66 & 2012 & Diffusion of safety innovations [90] & $\begin{array}{l}\text { Journal of Construction Engineering } \\
\text { and Management }\end{array}$ & 32 & 5 \\
\hline 27 & 2016 & $\begin{array}{l}\text { Human and technological requirements for BIM } \\
\text { and mobile AR implementation [91] }\end{array}$ & Facilities & 13 & 4 \\
\hline 49 & 2014 & BIM integration with mobile AR [92] & $\begin{array}{l}\text { Journal of Management in } \\
\text { Engineering }\end{array}$ & 19 & 4 \\
\hline 39 & 2015 & $\begin{array}{l}\text { Operational efficiency of construction equipment } \\
\text { [93] }\end{array}$ & $\begin{array}{l}\text { Journal of Computing in Civil } \\
\text { Engineering }\end{array}$ & 13 & 3 \\
\hline 40 & 2015 & AR for enhancing students' performance [94] & Advances in Engineering Education & 11 & 3 \\
\hline 62 & 2013 & Mixed reality for remote design review [95] & Visualization in Engineering & 16 & 3 \\
\hline
\end{tabular}

286 Note to table: Building information modelling: BIM; augmented reality: AR; social networking 287 services: SNS.

\subsection{Clustering and content analysis}

290 The sample of 57 full papers was carefully reviewed and classified based upon keyword 291 similarity to produce five clusters with clusters 1 to 5 including 3, 14, 13, 3 and 24 papers 292 respectively. The articles within each cluster were analysed in terms of relevance to: 293 adoption; compatibility; GIS; implementation; interoperability; Rogers theory; AR and VR; 294 and cloud-based technologies. Figure 4 demonstrates that clusters 2, 3 and 5 are those mainly 295 under discussion and thus the relevant sub-topics should be analysed further. Figure 5 shows 296 the results of word clouds for the three main clusters 2, 3 and 5. Clusters 1 and 4 are merged 297 with relative clusters to constitute three groups, namely: BIM adoption, GIS and VR/AR. 


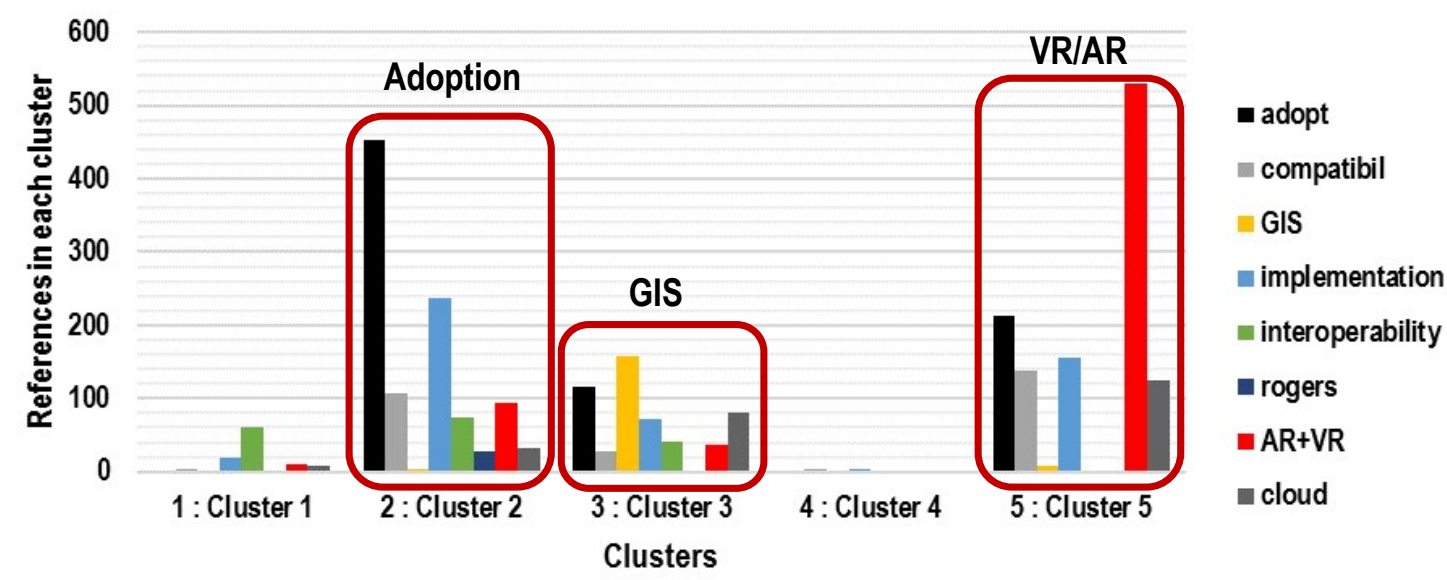

Figure 4. References in each cluster referring to the dominant referencing of adoption, GIS and VR/AR in clusters 2,3 and 5 respectively.

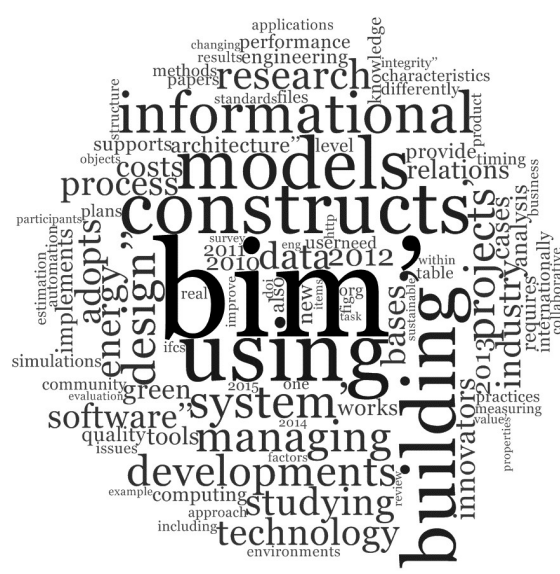

Cluster 2

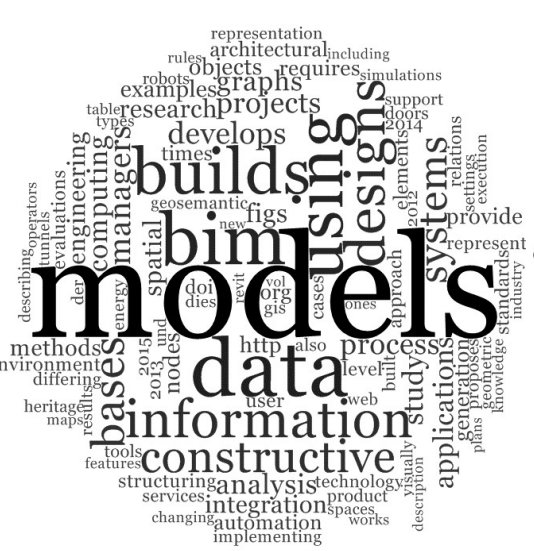

Cluster 3

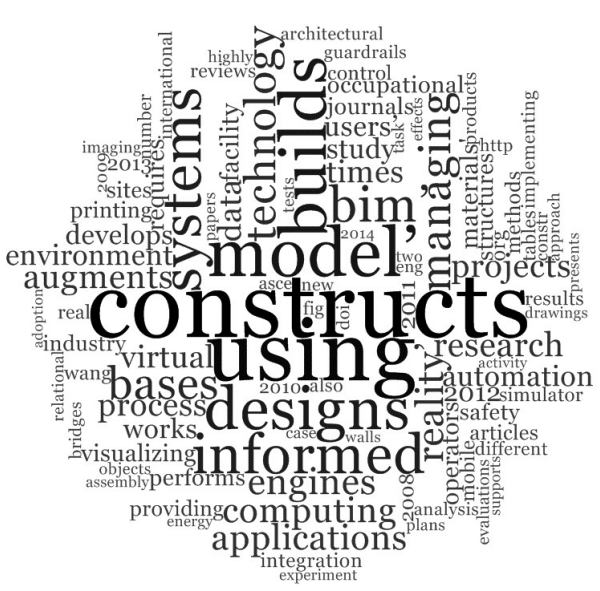

Cluster 5

Figure 5. Word clouds of the key clusters of the BIM-COM literature.

In order to identify the temporal trend in both the overall literature and the BIM-COM literature set, a time-based analysis strategy was applied to both data sets. Figures $6 \mathrm{a}$ and $6 \mathrm{~b}$ show that papers focused on the application of BIM in construction and architectural design before 2014. Figures $6 \mathrm{c}$ and $6 \mathrm{~d}$ show that data interchange is used co-concurrently with other key concepts post-2017. This shows that topics related to data handling, format and other interoperability issues will continue to be an important domain that requires careful investigation. 


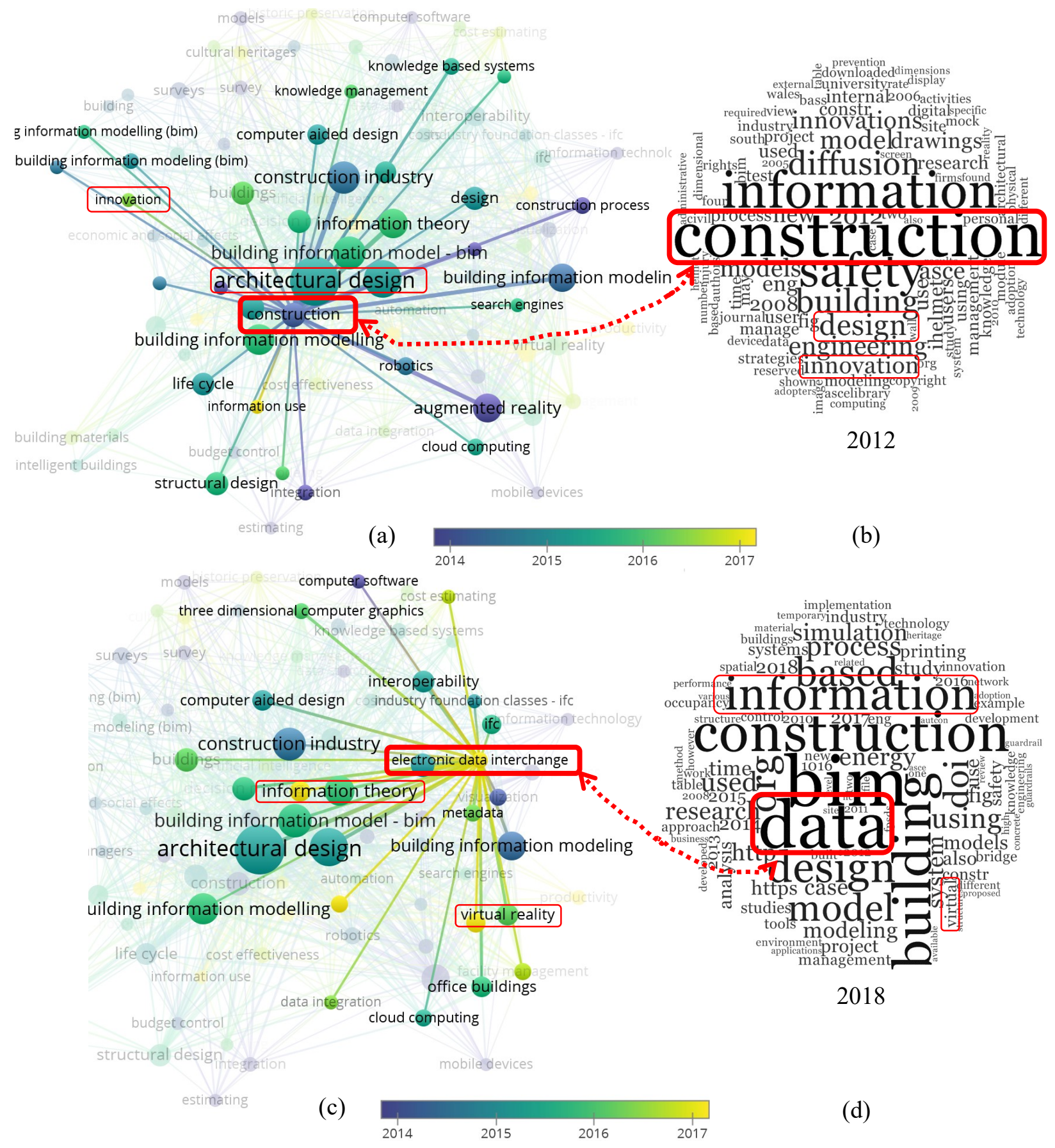

Figure 6. Key focus of the literature over time. (a) co-occurrence of construction and other high frequency words before 2014 in the overall literature; (b) Word clouds of key words within papers published in 2012 in the BIM-COM literature; (c) co-occurrence of electronic data interchange and other high frequency words after 2017 in the overall literature; (b) Word clouds of key words within papers published in 2018 in the BIM-COM literature.

Figure 7 presents the frequency of the main codes in the BIM-COM literature over two different periods of time: 2012 to 2015 and 2016 to 2018. It illustrates that the focus on interoperability increased by $90 \%$ in the later time period, and more particularly the interoperability of BIM with GIS increased by $85 \%$. In terms of theoretical investigations, the frequency of using Rogers theory and compatibility also increased in the later time period. 


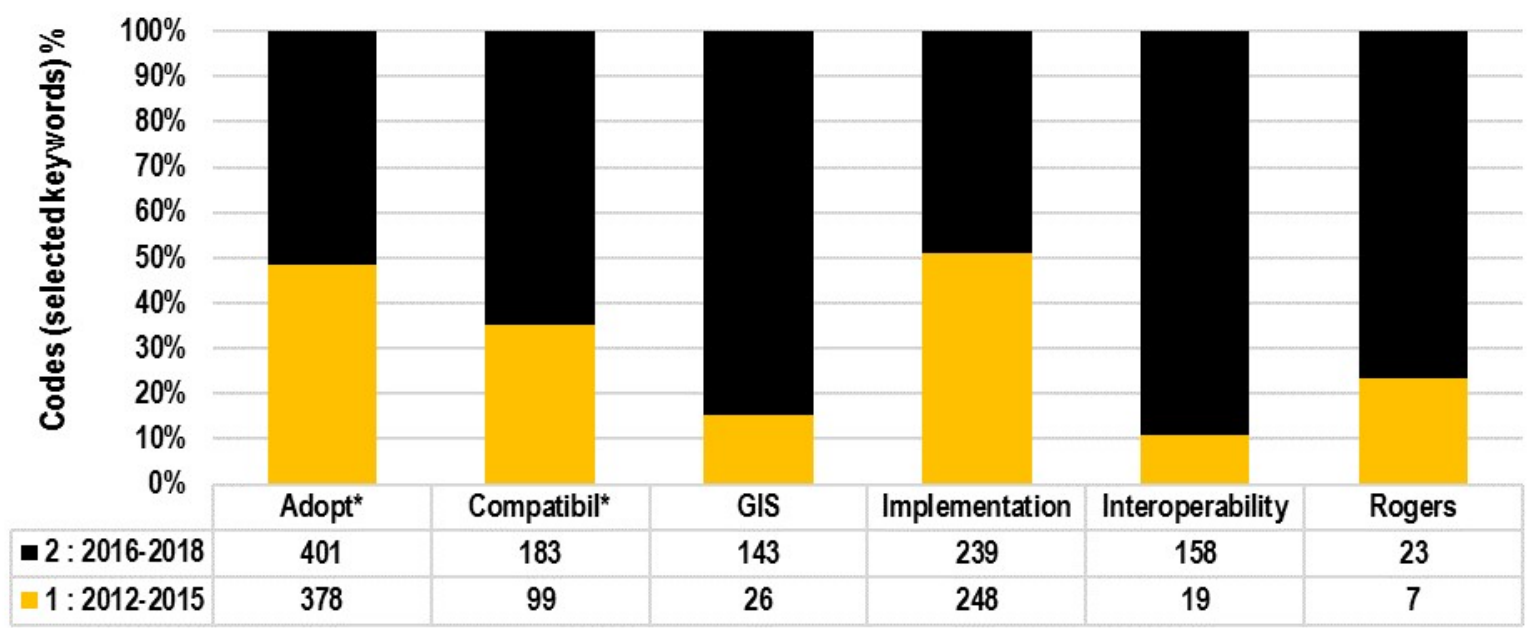

Figure 7. Comparing the number of references of keywords in two periods: (a) black: recent years from 2016-2018; (b) orange: early years of the BIM-COM literature from 2012-2015.

Each cluster was also analysed based on the year of publication, thus Table 2 shows the number of article references for each individual node (concept) by publication year, with a total of eight nodes analysed. The focus of the BIM-COM literature is seen to be 'adoption' and 'implementation' (nodes A and D) with frequencies of 779 and 487 respectively over the time period of the sample. The figures show that the integration of BIM with 'GIS' has received increased attention from 2016, while 'interoperability' and 'compatibility' display higher frequencies in 2017 and 2018, with almost half of the total frequency (282) of 'compatibility' being from references in 2018. These three clusters show little focus received in 2012 and 2013, whereas 'adoption' has been a focus of the BIM-COM literature from 2012 onwards.

Table 2. References coded into each node by year.

\begin{tabular}{|c|c|c|c|c|c|c|c|c|c|}
\hline & $\begin{array}{l}\text { A: } \\
\text { Adopt }\end{array}$ & $\begin{array}{l}\text { B: } \\
\text { Compatibil }\end{array}$ & $\begin{array}{l}\text { C: } \\
\text { GIS }\end{array}$ & $\begin{array}{l}\text { D: } \\
\text { Implementation }\end{array}$ & $\begin{array}{l}\text { E : } \\
\text { Interoperability }\end{array}$ & $\begin{array}{l}\text { F : } \\
\text { Rogers }\end{array}$ & $\begin{array}{l}\text { G: } \\
\text { AR+VR }\end{array}$ & $\begin{array}{l}\text { H: } \\
\text { Cloud }\end{array}$ & $\begin{array}{l}\text { Articles } \\
\text { per year }\end{array}$ \\
\hline $1: 2012$ & 76 & 4 & 0 & 9 & 0 & 0 & 15 & 0 & 3 \\
\hline $2: 2013$ & 90 & 38 & 2 & 61 & 1 & 3 & 352 & 107 & 9 \\
\hline $3: 2014$ & 36 & 19 & 13 & 63 & 6 & 1 & 173 & 6 & 9 \\
\hline $4: 2015$ & 176 & 38 & 11 & 115 & 12 & 3 & 10 & 11 & 8 \\
\hline $5: 2016$ & 10 & 10 & 74 & 32 & 11 & 0 & 33 & 12 & 5 \\
\hline $6: 2017$ & 124 & 35 & 42 & 26 & 83 & 12 & 1 & 14 & 7 \\
\hline $7: 2018$ & 267 & 138 & 27 & 181 & 64 & 11 & 90 & 96 & 16 \\
\hline Total & 779 & 282 & 169 & 487 & 177 & 30 & 674 & 246 & 57 \\
\hline
\end{tabular}

344 Noteworthy is that the integration of BIM with 'AR/VR' received considerable attention from 345 the sample authors in 2013 and 2014 even though 'interoperability' was not yet an issue.

346 When interoperability entered into the literature of BIM compatibility, the need to integrate

347 BIM with AR/VR in an automated manner became a prominent issue. In 2018, 90 references

348 were linked to AR/VR concepts; further investigation revealed that only seven articles paid

349 attention to virtual models in 2018. Two of those that frequently referenced to AR or VR

350 included Chu et al. [96] and Alsafouri and Ayer [97]. A total of 22 reference codes $(0.32 \%$

351 coverage) were found in the Chu et al. [96] article evaluating a simple AR BIM tool and 38

352 references codes $(0.36 \%$ coverage $)$ were found in the Alsafouri and Ayer [97] article. There

353 is no evidence showing why AR and VR have received more attention again recently. In 
addition, the desire to utilise AR/VR has not encouraged authors within the sample to examine or fully report upon the interoperability challenges of the AR and VR tools and BIM. Over the seven-year time period, the number of articles that discuss compatibility of BIM with AR and VR integration at least once in their article is 22 and 21 out of 57 respectively (just under $40 \%$ of our sample). Finally, the integration of BIM with Cloud received considerable attention in 2013 and 2018, which surprisingly shows a similar pattern to AR/VR integration.

\subsection{Critical content analysis and developing a theoretical base}

Table 3 illustrates the focus of each cluster. Three main themes were selected based upon the 364 initial screening of the selected papers. Theme 1 incorporates adoption, compatibility, implementation, interoperability and Rogers keywords. Theme 2 includes GIS, interoperability and cloud keywords. Theme 3 includes compatibility, implementation, cloud and VR/ AR keywords. The thematic analysis shows that Cluster A has a main focus on Theme 1; Cluster B focuses on Theme 2; and Cluster C focuses on Theme 3. These clusters and themes are the main pillars of a conceptual framework based on the DOI theory. Each cluster will be discussed separately.

Table 3. A conceptual matrix of clusters and themes as the basis of DOI theory including a summary of the referencing within each theme.

\section{Theme 1: Adoption Theme 2: GIS Theme 3: AR/VR}

\begin{tabular}{lllllllll} 
BIM-COM & $\begin{array}{l}\text { Total } \\
\text { references }\end{array}$ & $\begin{array}{l}\text { References } \\
\text { per article }\end{array}$ & $\begin{array}{l}\text { Total } \\
\text { references }\end{array}$ & $\begin{array}{l}\text { References } \\
\text { per article }\end{array}$ & $\begin{array}{l}\text { Total } \\
\text { references }\end{array}$ & $\begin{array}{l}\text { Articles } \\
\text { References } \\
\text { per article }\end{array}$ & $\begin{array}{l}\text { All } \\
\text { in each } \\
\text { cluster }\end{array}$ & $\begin{array}{l}\text { references } \\
\text { found }\end{array}$ \\
\hline CA: Cluster A & 901 & 64 & 109 & 8 & 473 & 34 & 14 & 1483 \\
CB: Cluster B & 254 & 20 & 280 & 22 & 215 & 17 & 13 & 749 \\
CC: Cluster C & 506 & 21 & 132 & 6 & 948 & 40 & 24 & 1586 \\
\hline
\end{tabular}

374

375

376

\subsubsection{Cluster $A$ with the focus on BIM adoption and interoperability}

Cluster A has 14 articles with a total of 1,483 references. Table 3 shows that the focus of cluster A is clearly on theme 1 , accounting for over $60 \%$ of all referencing within this cluster (901 out of 1,483). Within this theme, the number of references for adoption, compatibility, implementation, interoperability and Rogers keywords are 452, 108, 238, 74 and 29 references respectively, with adoption and implementation being most prominent. The average number of references per article is 64 , which is the highest across all themes and clusters.

This cluster discusses adoption and implementation concepts and relevant factors. For example, Davies and Harty [69] propose a set of scales to measure a user's beliefs about the outcome of BIM implementation, which include: effort and performance expectancy; facilitating conditions; compatibility; social influence; and attitude. They present an online self-completion questionnaire to measure compatibility with the user's working mode. Inherent within their scales is an ability to facilitate conditions such as 'compatibility' measures and ensure that BIM is compatible with the participant's 'core job function' and/or that BIM fits to their 'working style'. They observe a strong correlation between compatibility and performance expectancy. 
Table 4. Summary of selected papers of Cluster A.

ID Focus and method Context/business and Compatibility issues and/or measures country

60 Measurement of Sample of 1301 participants individual beliefs about in the UK (2013) BIM [69]

49 BIM translation to

Pilot study of a healthcare mobile AR applications facility management, [92]

46 Integrating AR with a telepresence tool for collaborative design [83]

33 Drivers of BIM adoption in design organizations [52]

19 BIM for energy modelling [53]

22 The adoption of 4D BIM [71]

\section{Experiments to measure} participants' perceptions about awareness and intentions to use (2014)

Sample of 162 architects

An historic and a new selected (2017)

Sample of 97 from UK from Korea to measure their behavioural intentions (2015) industrial construction case is construction industry (2017), questions formulated from Rogers theory [98]

Sample of 20 participants for interviews from Finnish construction industry including government, managers and BIM users (2018)

3 Integrating mobile BIM AR tool, an experimental study [96]

Evaluation of the modification of $2 \mathrm{D}$ drawings by 20 participants (2017)

Participants from three building cases for interviews from the Dutch construction industry (2018) with implementation [59]

1 Application of BIM in energy simulation [99]
Review of papers related to energy modelling and tools (e.g. AutoCAD tools) and/or files (e.g. IFC and gbXML) (2018)
Strong correlation between performance expectancy and compatibility.

Interoperability issues between servers; *.obj and *.json pipelines are time consuming and resulting in losing data.

Workspace awareness is a strong cognitive design tool for remote collaborative design. The scale of software is limited when the team number is high.

Strong correlation between perceived usefulness and perceived ease of use and compatibility.

Inconsistencies between two models, failing to use material properties in the gbXML format, remodelling required.

Significant association between compatibility and the adoption rate of 4D BIM. Limited variables used to measure compatibility.

Significance of interoperability highlighted; reported Euro $16 \mathrm{M}$ program for developing interoperable information ecosystem; interoperability became important from $90 \mathrm{~s}$.

Task efficiency was evaluated by mainly project and cost managers rather than technical users of BIM. The technical integration challenges were not identified.

Case projects with compatible BIM had consistent outcome; BIM compatibility affects the project network stability, suggest development of networkregulated BIM instructions.

Gap identified in conversation between BIM applications and energy modelling tools, e.g. EnergyPlus and DOE2 cannot directly import and read BIM files including gbXML and IFC. 
Son et al. [52] discuss the drivers of BIM adoption by examining architects' behavioural intentions using a modified technology acceptance model. They propose that compatibility has a strong correlation with perceived usefulness and perceived ease of use. They also realise that interoperability with $2 \mathrm{D}$ AutoCAD is a key issue relating to compatibility for BIM adoption. Son et al. [52] refer to compatibility as a technical issue of BIM and the individual's existing experiences. However, compatibility covers more complicated factors than the technical issues. Gledson and Greenwood [71] adopt a DOI model [98] and consider compatibility as one of the variables for assessing the 4D BIM innovation. To measure compatibility, they ask participants whether 4D BIM is compatible with their construction planning processes and report over $61 \%$ agreement from the participants (with a mean response of 3.58 for this measure on a 5 point Likert item scale) and a significant relationship between compatibility and the rate of 4D BIM adoption. While this is an important finding, the number of measures for compatibility remain limited and largely unexplored in the literature, highlighting a gap in how compatibility of BIM applications can be measured.

Aksenova et al. [54] examine the Finnish architecture, engineering and construction sectors by interviewing 20 participants. They adopt grounded theory to explore various events and actors related to Finnish BIM adoption from 1965 to 2015. They find that interoperability is a main concern from the 1990s, and an international alliance is established for interoperability (including 12 international organisations). The main mission of the International Alliance for Interoperability (IAI) was to set standards through industry foundation classes (IF), which IAI renamed to SmartBuilding although its agenda later extended. Aksenova et al. [54] report that software leaders (who are instrumental to BIM adoption) surprisingly do not support any standards for information technologies because they do not want users to change their systems. Investigations by Sepasgozar et al. [100] confirm that software vendors play a key role in the technology adoption process, but receive very little attention from the construction industry [101]. Papadonikolaki [59] investigates the Dutch construction industry, finding that in three selected building case studies the IFC, Native and CAD/PDF file types are exchanged and/or delivered. The intention is to explore the relationship between BIM adoption motivation and implementation. Discussion reveals that the BIM implementation process for the case studies is complicated using hybrid digital and paper based deliverable practice and that the implementation process still needs to be understood. Papadonikolaki [59] concludes that two of the selected cases have a consistent outcome in their project due to compatible BIM drivers. In this study [ibid], compatibility is shown to be a key determinant in the consistency of project outcomes.

Williams et al. [92] develop workflow to integrate BIM into mobile AR applications. They apply the workflow to a healthcare facility management case in Atlanta, US, and report that there are issues with Wavefront OBJ and JavaScript Object Notation data sets with *.obj and *.json extensions. These extensions were used as pipelines for integrating complex geometry from AutoCAD programs. The problem was that the conversation process resulted in losing data and inconsistencies in geometries of objects. In a different context, Gourlis and Kovacic [53] use the architecture and technical building services information modelled in Autodesk Revit for analysing energy efficiency in two cases using Energy Plus via Sketch Up and the Open Studio Plug-in.

Kamel and Memari [99] also examine the interoperability of BIM with energy modelling tools and report that there are major challenges which include: missing data; data recognition and error transference; and inconsistency of the file extensions generated by GBS and OpenStudio or EnergyPlus. In fact, the process of exchanging data from BIM tools to energy 
modelling and simulation tools such as Simergy, GBS, OpenStudio, DesignBuild, BEopt and eQuest is reported recently in 2019 as challenging or not fully automated. Kamel and Memari [99] state that data exchange is a difficult task and report observed issues in case studies, such as: missing or redundant data; data recognition, mapping and transferring issues; inconsistency in generated data; lack of required data or unwanted generated data; and manual re-entering of data. A recent publication by Mutis and Paramashivam [56] suggests that security tools should be employed for loss prevention, authentication, anomalous detection and format preservation.

Wang et al. [83] employ a remote collaborative design platform to increase the distributed cognition among designers by integrating AR and a telepresence system. They conduct experiments and report that the integrated systems increase social capital and interpersonal interactions. The research [ibid] also discusses that the system promotes workspace awareness linking to other factors such as environment, knowledge, exploration and action $\mathrm{BIM}$ and mobile AR, mentioning that interoperability between AutoCAD and other programs is required when the data needs to be shared with project stakeholders. They conclude that integration of several tools (such as AutoCAD (architecture and equipment), ERP and GIS) is required for realising the full potential of BIM in energy optimisation. The study [ibid] also clarifies that the issues related to data format and granularity are critical for industrial building projects, since a larger number of process, design and construction stakeholders are involved in the project over a short time span.

Elsewhere, Haoues et al. [103] suggest that compatibility and interoperability are key measures of system quality models and standards such as ISO 25010. Xu et al. [104] create a prototype to collect data from BIM for generation of the item costs for the bill of quantity. They suggest that successful cost estimation is possible if the data format is comprehensive and compatible. Other studies in this cluster suggest that BIM adoption should be facilitated in different businesses, such as green building BIM to meet sustainability objectives during the post-occupancy period [80].

\subsubsection{Cluster B with the focus on GIS interoperability}

Cluster B has 13 articles with a total of 749 references. Table 3 shows that this cluster promotes BIM and GIS integration with a total of 280 references and the highest number of referencing for GIS, interoperability and cloud at 158, 41 and 81 respectively. This accounts for over $37 \%$ of all referencing of this cluster (280 out of 749 ). The average reference per paper is 22 , which is the highest within the cluster and across all clusters for this theme.

While the integration of GIS and BIM is discussed each year of the sample, this becomes an important topic from 2016 (refer Table 2). For example, Fernández-Caramés et al. [105] integrate a real-time location system with GIS due to its powerful spatial databases. They [ibid] discuss that GIS is a successful technology due to its interoperability. Different data can be imported into GIS such as IFC models [106-108], Geography Markup Language (GML) [109,105], Keyhole Markup Language (KML), or ESRI's shapefiles (SHP) [105]. GML's simple feature profile and the SQL simple features describe similar geometries. GML is an XML encoding offered by the Open Geospatial Consortium (OGC) providing uniform geographic data storage and possibility of data exchanges [109]. Fernández-Caramés et al. [105] describe GIS as a 'fully human compatible' system because the design of the system is based on its usability, processing of geospatial data and potential to run queries [105]. For 
example, running a query can help to find a room or object with a given position and to retrieve a list of options. Fernández-Caramés et al. [105] describe GIS interoperability as outstanding among other systems. Although they carry out an experiment in an indoor area of building, the localisation data is not visualised in BIM and related compatibility issues are not discussed because they believe GIS has a better interoperability.

Table 5. Summary of selected papers of Cluster B.

\section{Focus and method Context/business and country Compatibility issues and/or measures}

\begin{tabular}{lll}
\hline BIM integration & Employment of COBie and & Interoperability between BIM and \\
with facilities & EcoDomus portal displaying & facilities management software.
\end{tabular}

management data via Navisworks. Case facilities management software.

databases [63] study: Cinematic Arts Complex, US (2015)

GIS integration with real-time indoor localization [105]

Utilising an autonomous navigation system in an indoor area; visualisation of the data in GIS (2016)

Applications of BIM in electrical systems design [110]

Data Fusion and IndoorGML core module [111]

Semantic web and BIM for representing heritage data [112]
Analysis of a case study of lighting design for a small office room inside a substation using an add-in tool to extract lighting information (2017)

Using AnchorNode of IndoorGML (2018)

Using LIDAR point cloud for modelling of an historic site in Northern Pakistan (2018)
GIS described as a 'fully human compatible' system with high interoperability with different formats such as IFC models, GML, KML, ESRI's SHP, GML's simple feature profile and the SQL simple features .

Issues in automating the extraction of feeder schedule with voltage changes, single line charts, size adjustment of cables and circuit breakers based on approved codes, lack of standards and freeware BIM tools.

CityGML suggested improving interoperability by developing topologybased data fusion techniques

Visualising a combination of structural and historical data; difficulties due to the differences in standards and heterogeneous data sets

Note: Geography Markup Language (GML); Keyhole Markup Language (KML); ESRI's shapefiles (SHP)

Vilgertshofer and Borrmann [113] also examine BIM capability of parametric design and confirm that the current BIM modelers are not flexible enough for defining parametric dependencies in complicated cases. They also confirm that GIS is compatible with the need to develop geometric-semantic modelling by using levels of detail (LoDs) [114]. However, they develop a model of capturing required knowledge for parametric modelling using a different set of tools. They use API of GrGen.Net for rewriting the graphs and rules, and also employ Autodesk Inventor as the 3D mechanical design communication due to its advanced parametric tools.

There are several unreported issues in terms of the use of LIDAR Data Exchange File (LAS) within a GIS environment which can be helpful for using point clouds at a building or a city scale. Reading and writing on LAS files in ArcGIS has been a big challenge for several years. While it is claimed that this problem is solved through either a GUI (see Figure 8) within ArcGIS or FME (see Figure 9) as a standalone software, this problem still exists as LAS files 
cannot be read or written. Indeed, both the GUI and FME are additional steps to change the file format from *.las to *.lasd. There is a question whether any change from *.lasd created for ArcGIS to .las format will keep the original attributes of the *.las file (refer to Figures 10 and 11).

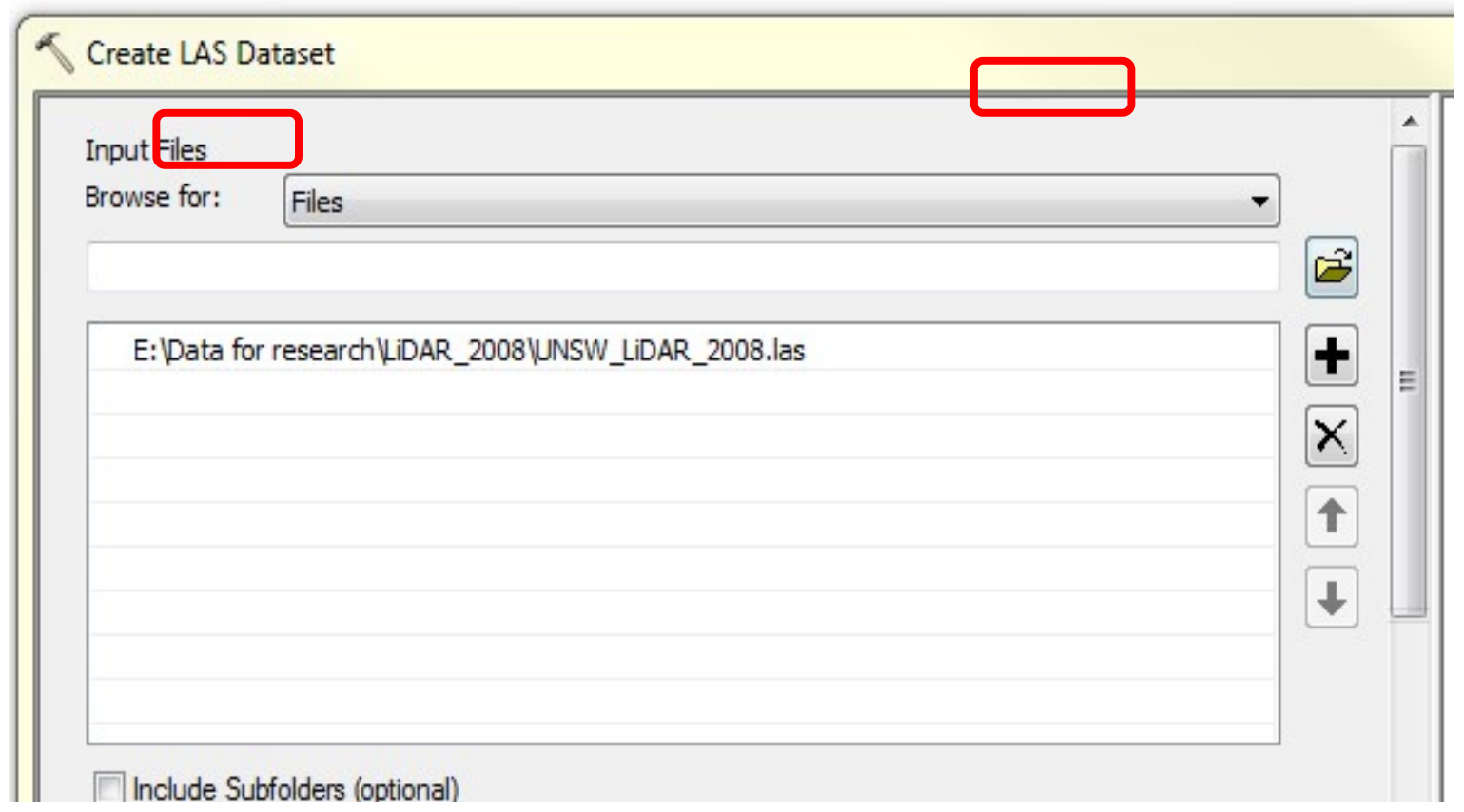

Figure 8. Conversion of *.las to *.lasd file as an additional step for ArcGIS to read *.las file by using a GUI in ArcGIS. Red boxes refer to an option for importing data and its detailed information.
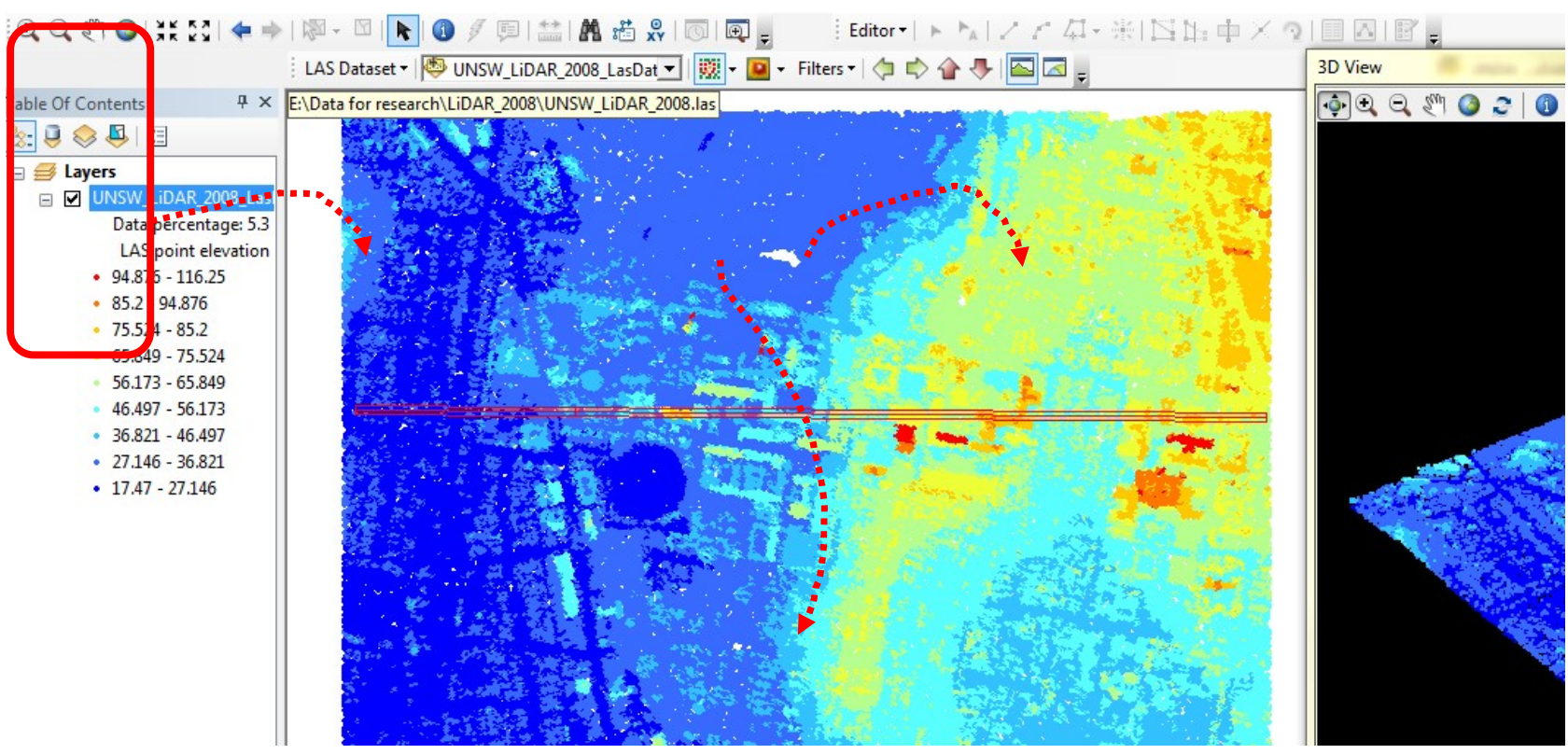

Figure 9. ArcGIS capability to only visualise the *.lasd file using the LAS dataset toolbar. 


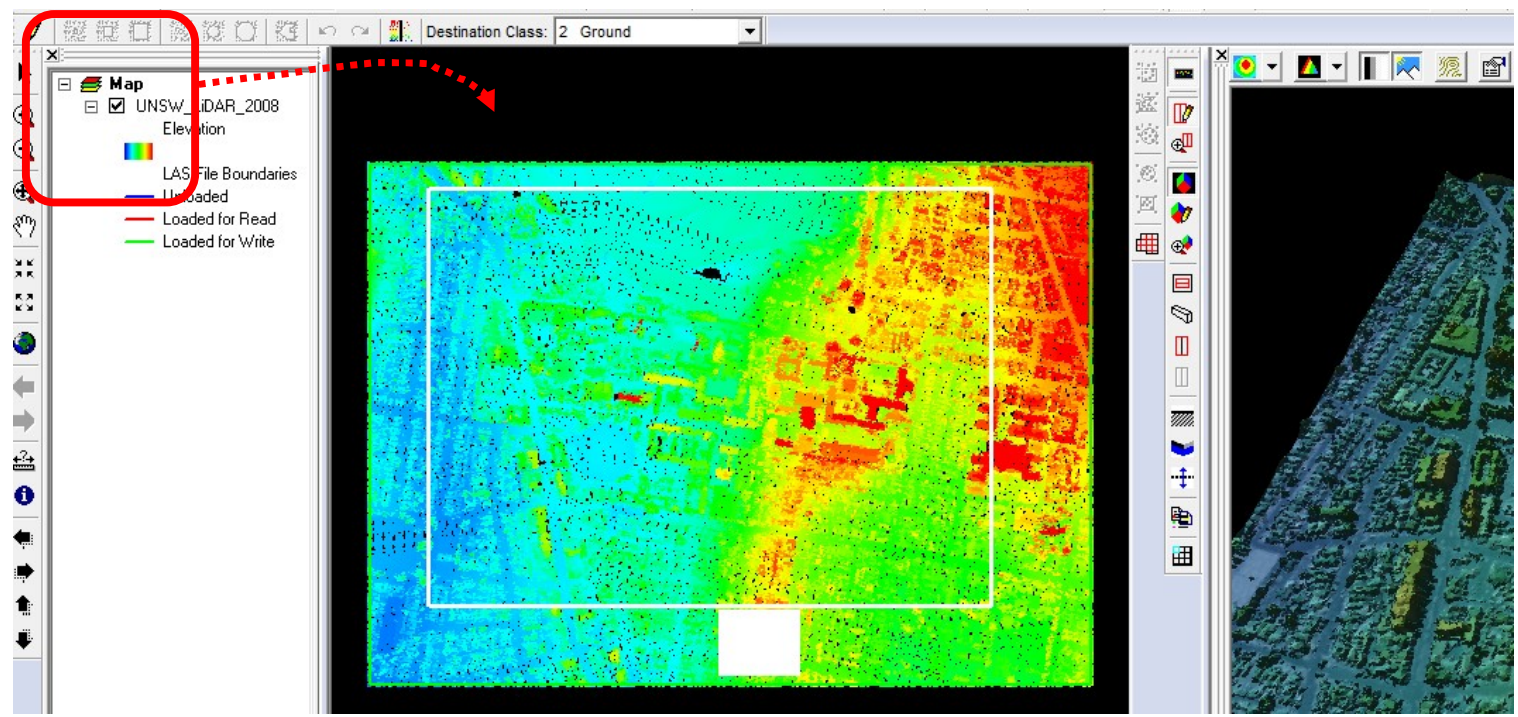

Figure 10. Required additional extension to ArcGIS for processing airborne lidar *.las file (such as classification and noise removal) in addition to the visualisation.
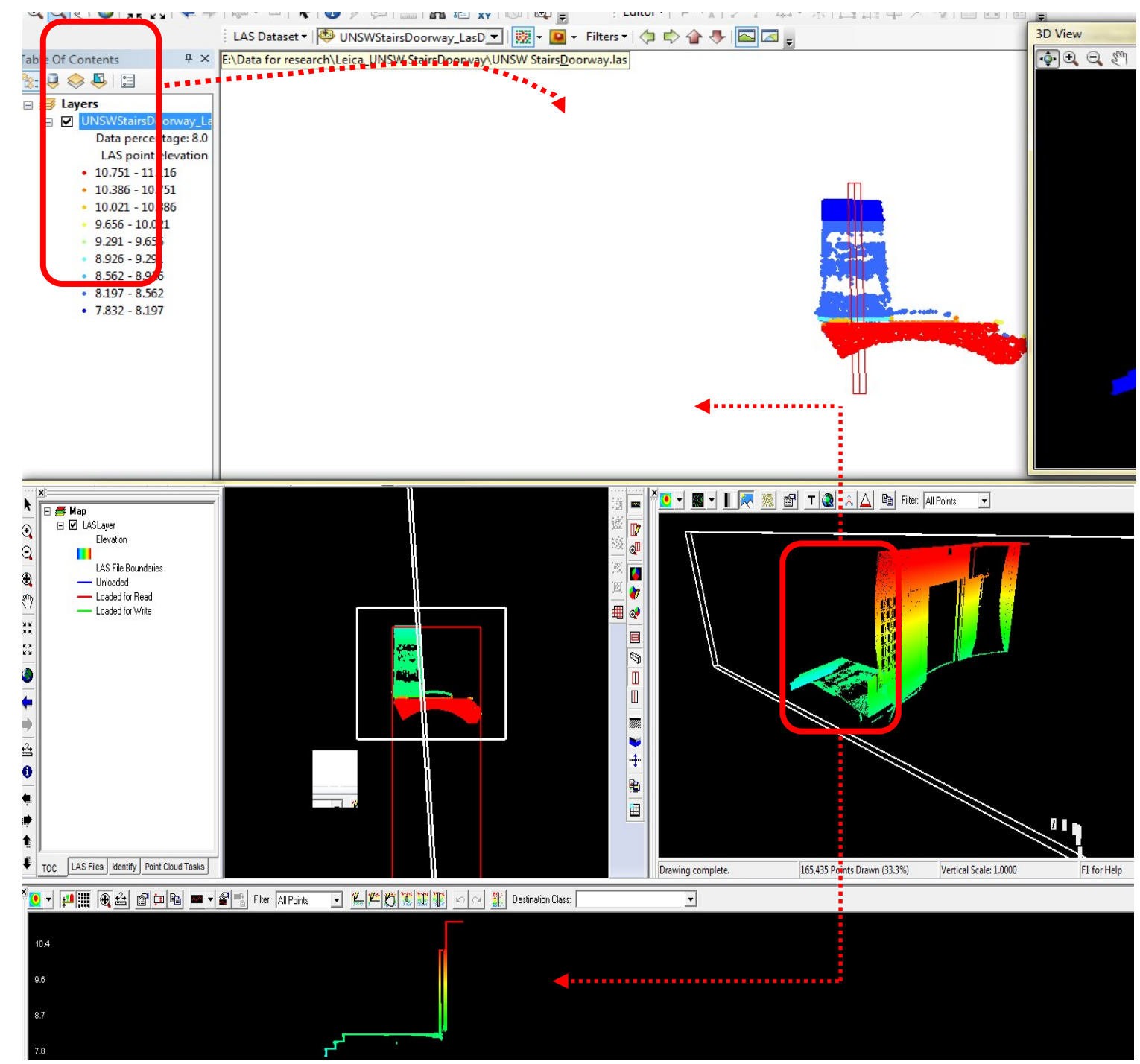

Figure 11. Terrestrial lidar data with a *.las file format of a selected building. 
Yue et al. [89] discuss that one single model cannot accurately provide detailed information for complex geo-analysis. They suggest that service standards should be extended including web processing service. However, they do not offer any solution for BIM compatibility. Ding, et al. [32] review applications of BIM and reveal a gap in integrating safety, quality and emissions into BIM during construction. Thus, they discuss approaches for quantifying these concepts, rather than the integration challenges.

Kensek [63] examines BIM compatibility with facility management systems including software packages and databases over time. Ding et al. [82] investigate BIM adoption factors in China using an integration with GIS. They find that 'compatibility' and 'integration' between BIM and other software packages are a critical issue in China. However, they [ibid] variable in their measurement scales, similar to BIM capability, motivation and behavioural intention.

Lee et al. [85] discuss a green template to be used in BIM for environmental assessment of a case building based on Korean standards. They outline that the process of green evaluation using BIM is time consuming due to the challenges of data conversation between software packages and the lack of data compatibility. Lee et al. [85] employ IMPACT as the current evaluation tool established by the UK Building Research Establishment (BRE) and note that some data formats are not supported by the energy analysis systems. They [ibid] report that the interoperability issue affects the reliability of embodied estimation and increases the processing time. Sönmez [115] reviews papers on the architectural applications of computer vision and machine learning and semantic modelling. It is suggested [ibid] that computer vision and BIM provide big data of the built environment. However, the main concern is how to analyse and use such information rich data sets. Noor et al. [112] create a model that represents cultural heritage data with the integration of semantic web and BIM. They [ibid] report that there are limitations to representing architectural objects and their construction methods in heritage cases. They also find a lack of standards or common ontology in BIM and three packages (CityGML, MIDAS and CIDOC-CRM) employed in their experimentations.

Du et al. [116] outline a synchronization system for updating BIM changes in VR Oculus Rift DK2 in an automatic manner, following their revelation of a general problem that the conversation between BIM, including the project design data, and VR models is difficult and time consuming. However, they report that this system should be tested on complex models. The speed of synchronization will be affected where there are many interdependent elements changed. They discuss two types of limitations, such as internal and external latency, including delay in data entry, transmission, processing, perception, evaluation, judgement, and response. Park et al. [111] also extend the list of limitations when examining logical and geometrical topological relations. They report that heterogenous data formats, models, spatial resolutions and geometric resolution methods are key barriers of an efficient data fusion practice.

\subsubsection{Cluster $C$ with the focus on $A R / V R$ interoperability}

Cluster $\mathrm{C}$ has 24 articles with a total of 1,586 references. Table 3 shows that the focus of cluster $\mathrm{C}$ is on theme 3 , accounting for $60 \%$ of all referencing of this cluster (948 out of 1,586). Within this theme, the number of references for compatibility, implementation, cloud and VR/AR are 139, 155, 124 and 530 respectively. The average number of references per 
Table 6. Summary of selected papers of Cluster C.

\begin{tabular}{lll}
\hline Focus and method & Context/business and country & Compatibility issues and/or measures \\
\hline $\begin{array}{l}\text { Compatible fall protection } \\
\text { tool for bridge maintenance }\end{array}\left[\begin{array}{l}\text { Using Autodesk Fusion 360 for } \\
\text { presenting guardrails for case } \\
\text { bridges in North Carolina (2018) }\end{array}\right.$ & $\begin{array}{l}\text { Suggested compatibility measures efficiency, } \\
\text { cost-effectiveness and safety which are to be } \\
\text { assessed prior to using fall protection systems. }\end{array}$ \\
Review of virtual models [97] & $\begin{array}{l}\text { Reviewing 119 papers from } \\
2005 \text { to 2015 (2018) }\end{array}$ & $\begin{array}{l}\text { Full automated method of exchanging } \\
\text { information between virtual models and other } \\
\text { systems ignored. }\end{array}$ \\
$\begin{array}{l}\text { Design of BIM-VR } \\
\text { synchronization system [116] }\end{array}$ & $\begin{array}{l}\text { Collection of BIM data from } \\
\text { Revit, transfer using Cloud } \\
\text { server based on IFC and display } \\
\text { in VR headset using a game } \\
\text { engine (2018) }\end{array}$ & $\begin{array}{l}\text { Very difficult conversation between BIM and } \\
\text { changes in VR headset. }\end{array}$ \\
\hline
\end{tabular}

\section{Discussion}

597 This review contributes to the prevailing body of knowledge by identifying the overlooked 598 factor of compatibility and clarifying the misconception of compatibility and interoperability 599 in the BIM-COM literature. While there has been extensive research conducted into 600 interoperability from a technical perspective $[117,118]$, there is a notable paucity of 601 investigation into developing DOI theory by analysing contextual factors regarding 602 compatibility. In fact, compatibility as a contextual theory has largely been ignored. This 603 paper identifies three main thematic groupings within the BIM-COM literature namely: BIM 604 adoption; GIS; and AR/VR. Moreover, the research also identifies a knowledge gap in terms 605 of developing a procedural model and relevant standards for integrating BIM with state-of-art 606 technologies over time. Volk et al. [119] report that interoperability challenges arise during 607 the lifetime of a building or infrastructure where the user still utilises the initial version of 608 information models. Arayici et al. [120] state that the cross-organisational interoperability 609 specification development adopts the Information Delivery Manual recommended by 610 BuildingSMART. However, their recommendations mainly revolve around data rather than 611 people and processes as the main parts of the adoption process [120]. Two approaches 612 regarding the 'compatibility' concept (refer to Table 7) are revealed and will be discussed 613 henceforth.

The first approach (contextual theory) uses compatibility as a measure of BIM diffusion at the organisational or sector levels in a specific context, focusing on the value of a user's organisation. While this is an important concept, first developed by Rogers in 1995, it has largely been ignored until 2012. The BIM-COM literature shows that in 2012 the number of references for compatibility is 4, but this frequency gradually increases to 138 in 2018 (refer to Table 2). This is because the concept is core to scholars' arguments since BIM diffusion is changing the target of adopters from architects to other disciplines, mainly construction contractors. In construction, a wider range of technologies and algorithms are being used and hence, it is important to use a compatible BIM with high interoperability. According to Haoues et al. [103] compatibility and interoperability are key measures of software product standards that have not been directly discussed in recent BIM standard investigations.

In this approach, compatibility is known as a key measurement of the rate of BIM adoption 

aforementioned papers investigate the important factor from the perspective of the user or differently in these articles, since there is not any unique measure defined for the compatibility concept for BIM or specific information technologies (IT) in construction.

Based on the identified factors in the compatibility literature, and experiences of GIS applications, a list of measures for assessing compatibility is provided. This list is critical for practitioners in assessing to what extent a proposed BIM application is compatible to their organisational values and it is useful to innovators for increasing the level of compatibility of BIM applications when offering a new system. The present review suggests future researchers must examine and improve compatibility and interoperability of BIM applications in different contexts [82]. There is also a contribution by identifying that integration of BIM with other methods, to extend BIM applications and therefore address current needs, will increase BIM adoption.

Cluster A suggests that compatibility and interoperability doggedly persist as major impediments for successful BIM adoption [53,69,52]. For example, Gourlis and Kovacic [53] argue that 'One-Platform-BIM', as a one-stop shop solution, is required to be widely and successfully used in different complicated projects. Theme 1 suggests the necessity of a mechanism for efficient data and model exchange between different users and software programs.

Within the BIM-COM cluster a variety of desirable BIM applications are mentioned, such as automated life cycle costing [53], spontaneous cost estimation for each item in the bill of quantity [104] and material emission footprints [53]. This work [cf. 22, 76] discusses that the existing data exchange challenge requires a long gestation period in construction. Further applications identified require the possibility of full integration of BIM with power system analysis tools, power demand estimation methods and/or renewable energy estimation algorithms [110]. For example, Farooq et al. [110] suggest the development of common standards and offer freeware applications of BIM (refer to cluster B). The systematic review presented here reveals that compatibility should be assessed prior to utilising information modelling applications in any construction project [116, 22]. For example, Zuluaga and Albert [22] suggest that departments of transportation in North Carolina should measure the compatibility of protection devices with their bridge projects prior to procurement. They propose the compatibility values of efficiency, cost-effectiveness and safety which should be addressed by virtual prototyping in their examinations. The content analysis specifically shows that previous studies complain of the difficulty of the conversation between BIM data and other technologies such as AR, VR and GIS [82]. For example, Du et al. [116] recently report that the lack of automated data transfer methods between BIM and VR makes the conversation between the two difficult. Du et al. [116] conclude that the latency between $\mathrm{BIM}$ and VR is one of the barriers for VR adoption in the construction projects.

As a future direction, BIM-COM could be further extended to explore the detailed barriers of adoption and implementation in different contexts which implies several directions for future investigations. These findings stimulate wider discourse as to whether the current means of analysing BIM adoption and implementation are correct? Since compatibility is a critical factor of technology diffusion, researchers should investigate the values of companies which may relate to the scale of the company in terms of size (small to large). In a specific context, Mostafa et al. [35] investigate barriers of BIM adoption in the prefabrication industry, but 
they also suggest that case study based investigations are required in this sector and other countries to identify context based factors.

The second approach (technical) uses compatibility and interoperability interchangeably or only focuses on interoperability of BIM with other software programs, which can be a measure of success of the implementation process. The present paper carefully defines compatibility as the main factor of BIM diffusion; this is different to interoperability which tends to enable different systems to work together with consideration to technical specifications, languages and standards. For example, the review shows that GIS users experience a higher interoperability when using GIS in their experimentations. FernándezCaramés et al. [105] describe GIS interoperability as outstanding among other systems and as a 'fully human compatible' system because the design of the system is based on its usability, processing of geospatial data and the potential to run queries, such as to help find a room or object with a given position and to retrieve a list of options. Fernández-Caramés et al. [105] point out that GIS supports different formats such as IFC models [106], Keyhole Markup Language (KML), ESRI's shapefiles (SHP), compatibility of GML Simple Features Profile and the Simple Features for SQL due to similarity of structure and geometries [105,109]. However, recent studies shows that BIM and GIS still cannot directly be linked together [121].

In the second approach, the interoperability of BIM with current systems and software packages is necessary to facilitate the implementation of BIM before the user becomes disheartened with using BIM or vendors offer replacement software, GUI or proxies that increase BIM implementation costs and frequently require additional staff training. This is in line with the literature mentioning that interoperability is a crucial requirement for increasing BIM adoption in the industry [62]. However, many articles do not discuss the interoperability issues. For example, in 2013 the number of references for AR/VR is 352 - the highest in the review period (refer to Table 2). Wang et al. [75] tend to explore implications of AR for future studies. Bae et al. [79] report that they could successfully generate 3D point cloud models of a target scene and claim that their technique is up to 35 times quicker than other Structure-from-Motion (SfM) algorithms. However, this study did not report challenges of compatibility of BIM with any other tools they used, since they practically did not develop any BIM. They suggest that a practitioner can create BIM by drawing lines on the photographs generated in their experimentations, but the issue of interoperability is not mentioned.

Several papers promote the integration of BIM and AR/VR [84,83,116]. For example, Irizarry et al. [84] suggest that the integration of BIM and mobile AR can enhance decision support systems and provide a collaborative environment for solving daily issues in facility management, particularly in complex facilities such as hospitals. However, recent studies confirm that the manual process of transferring data from BIM to VR displays is a timeconsuming task. Several studies express concerns about the lack of automated mechanism or efficient synchronization system for the conversation of rich data between BIM and VR [116]. In 2018, several papers within the study sample mainly discuss AR [96,97] whilst other key papers focus on VR [116,22]. Chu et al. [96] evaluate a mobile and cloud-based BIM AR tool by conducting a survey. They demonstrate that the existing $2 \mathrm{D}$ drawings can be modified using a marker tool and this may improve task efficiency in construction. Alsafouri and Ayer [97] review papers relevant to facilitation of information flow between stakeholders in virtual and real construction sites. They find that about $70 \%$ of articles examine a unidirectional flow of information, mainly from a construction site or a virtual model. They 
[ibid] also note that around $26 \%$ of the included papers mention a bidirectional information flow, in which the data is accessible from both a virtual model and real site. The review reveals that the majority of papers examine non-automated systems, and that automation receives less attention. This is why the interoperability issues of the relevant software programs were not fully identified previously. Du et al. [116] design an automated synchronization system for updating BIM changes in VR Oculus Rift DK2 and find a general problem that the conversation between BIM and VR models is difficult and time consuming. However, they report that this system should be tested on complex models. The speed of synchronization will be affected where many interdependent elements are changed simultaneously. In another paper, Zuluaga and Albert [22] propose a compatible system for bridge maintenance for fall protection.

Table 7. Summary of the clusters' arguments and gaps in the literature.

\begin{tabular}{|c|c|c|}
\hline $\begin{array}{l}\text { Two approaches in } \\
\text { BIM-COM literature }\end{array}$ & Core focus/argument & $\begin{array}{l}\text { Summary of issues for using BIM and } \\
\text { future directions }\end{array}$ \\
\hline $\begin{array}{l}\text { Approach } 1 \text { (contextual): } \\
\text { a measure of BIM at the } \\
\text { organisational and } \\
\text { community levels. }\end{array}$ & $\begin{array}{l}\text { Concepts of BIM } \\
\text { diffusion, compatibility } \\
\text { at organisational level; } \\
\text { investigation of BIM } \\
\text { adoption rate. }\end{array}$ & $\begin{array}{l}\text { Reported challenges of: compatibility } \\
\text { issues with different stakeholders; } \\
\text { difficulty of data exchange; missing or } \\
\text { redundant data; data recognition, mapping } \\
\text { and transferring issues; inconsistencies in } \\
\text { generated data; lack of required data or } \\
\text { unwanted generated data and manual re- } \\
\text { entering data; authentication; anomalous } \\
\text { detection; and format preserving. } \\
\text { Use of BIM for productivity measures, cost } \\
\text { estimating, cultural heritage and facility } \\
\text { management. }\end{array}$ \\
\hline $\begin{array}{l}\text { Approach } 2 \text { (technical): } \\
\text { a measure of BIM } \\
\text { implementation and its } \\
\text { integration with other } \\
\text { systems, including GIS or } \\
\text { papers inspired from GIS } \\
\text { practices and reference } \\
\text { these papers. }\end{array}$ & $\begin{array}{l}\text { Interoperability at } \\
\text { technical levels; cases } \\
\text { from integration of BIM } \\
\text { and GIS; facilitation of } \\
\text { BIM implementation } \\
\text { and extension of BIM } \\
\text { applications }\end{array}$ & $\begin{array}{l}\text { Heterogenous data models, formats, } \\
\text { different spatial resolutions, and geometric } \\
\text { representation methods, delay in data entry, } \\
\text { transmission, processing, perception, } \\
\text { evaluation, judgement, response, and } \\
\text { overall electronic data interchange, } \\
\text { specifically for energy saving and life cycle } \\
\text { assessment tools with BIM. }\end{array}$ \\
\hline
\end{tabular}

741

742

743

744

745

746

747

The value proposition on interoperability is confirmed by previous studies [61]. The review shows that there is a large gap in compatibility investigations and interoperability issues in terms of the integration of BIM applications and energy modelling and carbon embodied estimation tools, including faulty data exchange and interoperability $[99,122,123,53,85]$. Currently, the data from BIM applications cannot be directly used in energy modelling tools; data re-entry is necessary and/or employment of different GUIs such as OpenStudio, DesignBuilder, Hevacomp, Simergy, BEopt for EnergyPlus, and GBS, eQuest, and RIUSKA for DOE2 [99,124,125]. The conversation between BIM and energy modelling tools results in data loss and is experienced as a time-consuming practice [99,53]. Recent papers frequently suggest that future studies should resolve the current challenges of interoperability of BIM with energy saving and life cycle assessment tools [Muller [25].

As an additional future direction, all relevant technologies being used by different companies in the construction process should be investigated and classified to find out the various 
interoperability needs of the different businesses in construction. In fact, there is a need to identify how the process of integrating GIS, AR/VR or 3D printing, or the exchange of data between different BIM authoring programs such as Revit and Tekla, can be fully automated to address business needs and facilitate the diffusion process. For example in 2019, Sacks et numerous errors are encountered. These include the erroneous process of importing grid lines that were assigned into IFC 'proxy' objects, and thus were unable to exchange some of nonstandard cross-sections using IFC. The current practices of 3D printing and robotic construction show that BIM has the potential to generate the required nodes and edges of a 3D information model, which can automatically provide deposition, idle and rotation of extruder to minimize construction time and optimise a robot arm or a 3D printer extruder path [126]. However, there are serious limitations in using the current prototypes for robotic control with different algorithms and movement mechanisms reported in 2018 [127].

Mzyece et al. [128] recommend that future studies should concentrate focus on determining the degree of interoperability between BIM and the construction design and management obligations and regulations to facilitate BIM adoption in a proactive manner. While IoT is increasingly being used in construction, the literature expounds a desire to move towards full integration of AR/VR [116], point clouds, GIS, IoT, RFID [32] with BIM [60] and BIM Cloud [56]. More investigations are also required to develop semantic web technologies empowered by DF, SPARQL, OWL and SKOS to convey meaning between BIM and GIS, since these technologies are developing and need to further mature [129]. The review also illustrates concerns regards applying machine learning, computer vision, semantic modelling and classification on the rich source of information of BIM [115]. Wu [130] also suggests the development of different algorithms to classify each object in an IFC model automatically using deep learning. The prevailing lack of discourse between these technologies and BIM is observed as a key factor impeding the adoption rate of advanced technologies such as VR [116]. The review also suggests developing data fusion methods for geometric and spatial data including topological relations of spatial objects [111].

This paper presents avenues for future studies linked to each identified theme which can help to facilitate the full application of BIM. This will occur when BIM potential for data and model exchange is increased. Another important issue is related to legacy systems [131], where the organisation still wishes to use previous or outdated systems due to internal values and policy. This issue is related to the nature of an organisation and their tasks and missions, where advanced systems are not desirable to the organisation. This should be investigated as a compatibility issue. Costin and Eastman [117] provide some examples, such as the use of 8inch floppy disks by the Department of the Treasury when using assembly language code (ASM). In general, the reasons can be dollar saving, security or any other limitation. Therefore, compatibility and interoperability interfere at some points and should be investigated as future directions.

\section{Conclusions}

This paper aimed to identify and analyse articles related to compatibility as the main component of DOI theory which should be examined over time and in different contexts. The literature sources around this concept were identified and the BIM compatibility (BIM-COM) database including these relevant articles was created. This database showed an important gap in BIM adoption theory when considering the key measures of compatibility and interoperability in a systematic way. A total number of 131 articles were analysed to explore 
trends over time and specifically 57 articles were selected based on the BIM-COM selected criteria for a detailed critical content analysis (cluster and thematic analysis) which would lead to the development of a deeper understanding of the current challenges in the literature and future directions. The cluster analysis resulted in three main clusters (A, B, and C) which were critically analysed against three main themes of BIM adoption, GIS and VR/AR interoperability issues.

This paper presented a conceptual framework, including main clusters and themes, to assist in extending and applying the DOI theory. It also elaborates upon how interoperability and compatibility are closely, and sometimes interchangeably, used in the BIM-COM literature. Contributions are made to the body of knowledge by identifying three themes and distinguishing the differences of these two critical concepts. Interoperability needs to be considered as one of the technology adoption model measures for successful BIM implementation at the technical level. The BIM-COM literature shows that articles examine examination of interoperability issues should be investigated at regular temporal intervals (possibly annually) because software programs are advancing exponentially and simultaneously, and new compatibility issues occur as software (and integration of different software) progressively develops. However, the present systematic review illustrates that the concept of compatibility has been overlooked. This concept is a contextual factor which can be used to measure BIM adoption at the organisational level.

The present article suggests that future studies should examine compatibility as a key construct of the BIM adoption model and specific measures should be determined by scholars to enable practitioners to predict the level of BIM compatibility in different contexts. In addition, the paper also reviews the perceived challenges of interoperability as the key practical barriers of BIM implementation and how the issues have shifted from basic formats in early 2000 to the variety of current complicated interoperability issues related to emerging digital technologies. A large knowledge gap is identified for improving compatibility in construction organisations. The compatibility concept should also be understood by construction companies in order to assess their needs, experience and infrastructures before they make the final BIM adoption decision. The study's findings help to extend BIM applications and speed up the adoption rate by easy conversations of data and model among stakeholders with different needs and using different formats.

\section{References}

[1] E. Rogers, Diffusion of Innovations, Free Press, New York, 1983. ISBN: 0029266505.

[2] S. Kale, D. Arditi, Innovation diffusion modeling in the construction industry, Journal of Construction Engineering and Management 136 (3) (2009) pp. 329-340. https://doi.org/10.1061/(ASCE)CO.1943-7862.0000134

[3] N. Sergeeva, N. Liu, Social construction of innovation and the role of innovation brokers in the construction sector, Construction Innovation (2019). https://doi.org/10.1108/CI-02-2019-0016

[4] E.M. Rogers, Diffusion of Innovations, Free Press, New York, 2003. ISBN: 0743222091.

[5] I.-L. Wu, M.-L. Chiu, Organizational Applications of IT Innovation and Firm's Competitive Performance: A Resource-Based View and the Innovation Diffusion Approach, Journal of Engineering and Technology Management (0) (2014). https://doi.org/10.1016/j.jengtecman.2014.09.002 

Innovation Adoption in Organizations, Journal of Engineering and Technology Management 29 (3) (2012) pp. 358-390. https://doi.org/10.1016/j.jengtecman.2012.03.007

858 [7] S.M.E. Sepasgozar, M. Loosemore, S.R. Davis, Conceptualising information and equipment technology adoption in construction: A critical review of existing research, Engineering, Construction and Architectural Management 23 (2) (2016) pp. 158-176. https://doi.org/10.1108/ECAM-05-2015-0083

862 [8] Y. Arayici, P. Coates, L. Koskela, M. Kagioglou, C. Usher, K. O'Reilly, Technology 863 Adoption in the BIM Implementation for Lean Architectural Practice, Automation in Construction 20 (2) (2011) pp. 189-195. https://doi.org/10.1016/j.autcon.2010.09.016

865 [9] S. Terreno, C. Anumba, E. Gannon, C. Dubler, The benefits of BIM integration with 866 facilities management: A preliminary case study, Computing in Civil Engineering 2015, 2015, pp. 675-683. https://doi.org/10.1061/9780784479247.084

868 [10] D. Bryde, M. Broquetas, J.M. Volm, The Project Benefits of Building Information 869 Modelling (BIM), International Journal of Project Management 31 (7) (2013) pp. 971-980. https://doi.org/10.1016/j.ijproman.2012.12.001

[11] Y. Chen, H. Dib, R.F. Cox, M. Shaurette, M. Vorvoreanu, Structural equation model of building information modeling maturity, Journal of Construction Engineering and Management 142 (9) (2016). https://doi.org/10.1061/(ASCE)CO.1943-7862.0001147

874 [12] B. Succar, Building information modelling framework: A research and delivery foundation for industry stakeholders, Automation in Construction 18 (3) (2009) pp. 357-375. https://doi.org/10.1016/j.autcon.2008.10.003

877 [13] A. Ahankoob, K. Manley, C. Hon, R. Drogemuller, The impact of building information modelling (BIM) maturity and experience on contractor absorptive capacity, 879 Architectural Engineering and Design Management (2018) pp. 1-18. https://doi.org/10.1080/17452007.2018.1467828

$881 \quad$ [14] F.R. Cecconi, N. Moretti, S. Maltese, L.C. Tagliabue, A BIM-Based Decision Support System for Building Maintenance, Advances in Informatics and Computing in Civil and 883 Construction Engineering, Springer, 2019, pp. 371-378. https://doi.org/10.1007/978-3-030$884 \quad 00220-6 \quad 44$

885 [15] E. Oliveira, C.F. Júnior, F. Correa, Simulation of construction processes as a link 886 between BIM models and construction progression on-site, Advances in Informatics and 887 Computing in Civil and Construction Engineering, Springer, 2019, pp. 11-18. https://doi.org/10.1007/978-3-030-00220-6 2

[16] R. Masood, M.K.N. Kharal, A.R. Nasir, Is BIM adoption advantageous for construction industry of Pakistan?, Procedia Engineering 77 (2014) pp. 229-238. https://doi.org/10.1016/j.proeng.2014.07.021

[17] J. Rogers, H.-Y. Chong, C. Preece, Adoption of building information modelling technology (BIM) perspectives from Malaysian engineering consulting services firms, Engineering, Construction and Architectural Management 22 (4) (2015) pp. 424-445. https://doi.org/10.1108/ECAM-05-2014-0067

896 [18] M. Abubakar, Y. Ibrahim, D. Kado, K. Bala, Contractors' perception of the factors affecting Building Information Modelling (BIM) adoption in the Nigerian Construction Industry, Computing in Civil and Building Engineering (2014), 2014, pp. 167-178. https://doi.org/10.1061/9780784413616.022

900 [19] E.M. Rogers, Diffusion of Innovations, Simon and Schuster, 2010. ISSN: 9011451602472.

902 [20] M. Kassem, B. Succar, Macro BIM adoption: Comparative market analysis,

903 Automation in Construction 81 (2017) pp. 286-299.

904 https://doi.org/10.1016/j.autcon.2017.04.005 

small and medium construction organisations in Australia, Engineering, Construction and Architectural Management 26 (2) (2018) pp. 154-183. https://doi.org/10.1108/ECAM-042017-0064

[22] C.M. Zuluaga, A. Albert, Preventing falls: Choosing compatible Fall Protection Supplementary Devices (FPSD) for bridge maintenance work using virtual prototyping, Safety Sciences 108 (2018) pp. 238-247. https://doi.org/10.1016/j.ssci.2017.08.006 [23] S. Eria, R.B. McMaster, GIS diffusion in Uganda, International Journal of Geographical Information Science 31 (5) (2017) pp. 884-906.

https://doi.org/10.1080/13658816.2016.1242131

915 [24] J.H. Jeppesen, E. Ebeid, R.H. Jacobsen, T.S. Toftegaard, Open geospatial

916 infrastructure for data management and analytics in interdisciplinary research, Computers and 917 Electronics in Agriculture 145 (2018) pp. 130-141.

918 https://doi.org/10.1016/j.compag.2017.12.026

919 [25] M.F. Muller, F. Esmanioto, N. Huber, E.R. Loures, O.C. Junior, A systematic literature review of interoperability in the green Building Information Modeling lifecycle, Journal of Cleaner Production 223 (2019) pp. 397-412.

https://doi.org/10.1016/j.jclepro.2019.03.114

[26] S.M. Sepasgozar, S. Davis, Construction technology adoption cube: An investigation on process, factors, barriers, drivers and decision makers using NVivo and AHP analysis, Buildings 8 (6) (2018). https://doi.org/10.3390/buildings 8060074

[27] W.E. Bijker, How is technology made? That is the question!, Cambridge Journal of Economics 34 (1) (2010) pp. 63-76. https://doi.org/10.1093/cje/bep068

928 [28] A. Lema, R. Lema, Technology transfer in the clean development mechanism: 929 Insights from wind power, Global Environmental Change 23 (1) (2013) pp. 301-313. https://doi.org/10.1016/j.gloenvcha.2012.10.010

[29] D. Arditi, S. Kale, M. Tangkar, Innovation in construction equipment and its flow into the construction industry, Journal of Construction Engineering and Management 123 (4) (1997) pp. 371-378. https://doi.org/10.1016/j.autcon.2013.08.012

[30] M.J. Skibniewski, E.K. Zavadskas, Technology development in construction: a continuum from distant past into the future, Journal of Civil Engineering and Management 19 (1) (2013) pp. 136-147. https://doi.org/10.3846/13923730.2012.756060 [31] R. Sacks, I. Kaner, C.M. Eastman, Y.-S. Jeong, The Rosewood experiment: Building information modeling and interoperability for architectural precast facades, Automation in Construction 19 (4) (2010) pp. 419-432. https://doi.org/10.1016/j.autcon.2009.11.012

[32] L. Ding, Y. Zhou, B. Akinci, Building Information Modeling (BIM) application framework: The process of expanding from $3 \mathrm{D}$ to computable $\mathrm{nD}$, Automation in Construction 46 (0) (2014) pp. 82-93. https://doi.org/10.1016/j.autcon.2014.04.009 Building Information Modeling (BIM): A bibliometric approach, Automation in Construction 84 (2017) pp. 195-206. https://doi.org/10.1016/j.autcon.2017.09.011

946 [34] M.K. Najjar, K. Figueiredo, A.C.J. Evangelista, A.W.A. Hammad, V.W.Y. Tam, A. 947 Haddad, Life cycle assessment methodology integrated with BIM as a decision-making tool 948 at early-stages of building design, International Journal of Construction Management (2019), pp. 1-15. https://doi.org/10.1080/15623599.2019.1637098

[35] S. Mostafa, K.P. Kim, V.W.Y. Tam, P. Rahnamayiezekavat, Exploring the status, benefits, barriers and opportunities of using BIM for advancing prefabrication practice, International Journal of Construction Management 20 (2) (2020) pp. 146-156. https://doi.org/10.1080/15623599.2018.1484555

[36] A. Costin, A. Adibfar, H. Hu, S.S. Chen, Building Information Modeling (BIM) for 
transportation infrastructure: Literature review, applications, challenges, and recommendations, Automation in Construction 94 (2018) pp. 257-281. https://doi.org/10.1016/j.autcon.2018.07.001

$958 \quad$ [37] R. Eiris, M. Gheisari, B. Esmaeili, Desktop-based safety training using 360-degree

959 panorama and static virtual reality techniques: A comparative experimental study, Automation in Construction 109 (2020). https://doi.org/10.1016/j.autcon.2019.102969 [38] J. Wolfartsberger, Analyzing the potential of Virtual Reality for engineering design review, Automation in Construction 104 (2019) pp. 27-37.

963 https://doi.org/10.1016/j.autcon.2019.03.018

964 [39] I. Awolusi, E. Marks, M. Hallowell, Wearable technology for personalized 965 construction safety monitoring and trending: Review of applicable devices, Automation in 966 Construction 85 (2018) pp. 96-106. https://doi.org/10.1016/j.autcon.2017.10.010

967 [40] S. Shirowzhan, S.M. Sepasgozar, H. Li, J. Trinder, P. Tang, Comparative analysis of 968 machine learning and point-based algorithms for detecting 3D changes in buildings over time 969 using bi-temporal lidar data, Automation in Construction 105 (2019). https://doi.org/10.1016/j.autcon.2019.102841

[41] S. Shirowzhan, S.M. Sepasgozar, Spatial analysis using temporal point clouds in advanced GIS: methods for ground elevation extraction in slant areas and building classifications, ISPRS International Journal of Geo-Information 8 (3) (2019). https://doi.org/10.3390/ijgi8030120

975 [42] S.M. Sepasgozar, P. Forsythe, S. Shirowzhan, Evaluation of terrestrial and mobile 976 scanner technologies for part-built information modeling, Journal of Construction 977 Engineering and Management 144 (12) (2018). https://doi.org/10.1061/(ASCE)CO.19437862.0001574

[43] H.S. Ko, M. Azambuja, H. Felix Lee, Cloud-based materials tracking system prototype integrated with radio frequency identification tagging technology, Automation in Construction 63 (2016) pp. 144-154. https://doi.org/10.1016/j.autcon.2015.12.011

[44] H. Li, G. Chan, T. Huang, M. Skitmore, T.Y.E. Tao, E. Luo, J. Chung, X.S. Chan, Y.F. Li, Chirp-spread-spectrum-based real time location system for construction safety management: A case study, Automation in Construction 55 (2015) pp. 58-65. https://doi.org/10.1016/j.autcon.2015.03.024

[45] J. Fu, E. Jenelius, H.N. Koutsopoulos, Identification of workstations in earthwork operations from vehicle GPS data, Automation in Construction 83 (2017) pp. 237-246. https://doi.org/10.1016/j.autcon.2017.08.023

[46] V. Venkatesh, C. Speier, M.G. Morris, User acceptance enablers in individual decision making about technology: Towards an integrated model, Decision Sciences 33 (2) (2002) pp. 297-316. https://doi.org/10.1111/j.1540-5915.2002.tb01646.x

[47] F.D. Davis, V. Venkatesh, A critical assessment of potential measurement biases in the technology acceptance model: Three experiments, International Journal of Human Computer Studies 45 (1) (1996) pp. 19-45. https://doi.org/10.1006/ijhc.1996.0040

[48] S.M.E. Sepasgozar, M. Loosemore, The role of customers and vendors in modern construction equipment technology diffusion, Engineering, Construction and Architectural Management 24 (6) (2017) pp. 1203-1221. https://doi.org/10.1108/ECAM-06-2016-0149

[49] R. Ahuja, A. Sawhney, M. Jain, M. Arif, S. Rakshit, Factors influencing BIM adoption in emerging markets-the case of India, International Journal of Construction Management (2018) pp. 1-12. https://doi.org/10.1080/15623599.2018.1462445 An empirical study of Taiwan, Journal of Building Engineering 20 (2018) pp. 337-343. https://doi.org/10.1016/j.jobe.2018.08.007

1004 [51] J.J. McArthur, N. Shahbazi, R. Fok, C. Raghubar, B. Bortoluzzi, A. An, Machine 
learning and BIM visualization for maintenance issue classification and enhanced data collection, Advanced Engineering Informatics 38 (2018) pp. 101-112. https://doi.org/10.1016/j.aei.2018.06.007

[52] H. Son, S. Lee, C. Kim, What Drives the Adoption of building information modeling in design organizations? An empirical investigation of the antecedents affecting architects' behavioral intentions, Automation in Construction 49, Part A (0) (2015) pp. 92-99. https://doi.org/10.1016/j.autcon.2014.10.012

[53] G. Gourlis, I. Kovacic, Building Information Modelling for analysis of energy efficient industrial buildings: A case study, Renewable and Sustainable Energy Reviews 68 (2017) pp. 953-963. https://doi.org/10.1016/j.rser.2016.02.009

1014

1015

1016

1017 [54] G. Aksenova, A. Kiviniemi, T. Kocaturk, A. Lejeune, From Finnish AEC knowledge ecosystem to business ecosystem: lessons learned from the national deployment of BIM, Construction Management and Economics (2018), pp. 317-335.

https://doi.org/10.1080/01446193.2018.1481985

[55] X. Wang, P.S. Dunston, Compatibility issues in Augmented Reality systems for AEC: An experimental prototype study, Automation in Construction 15 (3) (2006) pp. 314-326. https://doi.org/10.1016/j.autcon.2005.06.002

[56] I. Mutis, A. Paramashivam, Cybersecurity management framework for a cloud-based BIM model, Advances in Informatics and Computing in Civil and Construction Engineering, Springer, 2019, pp. 325-333. https://doi.org/10.1007/978-3-030-00220-6 39

[57] P.C. Jha, R. Kaur, S. Bali, S. Madan, Optimal component selection approach for faulttolerant software system under CRB incorporating build-or-buy decision, International Journal of Reliability, Quality and Safety Engineering 20 (6) (2013). https://doi.org/10.1142/S0218539313500241 critical systems, International Journal on Software Tools for Technology Transfer 20 (4) (2018) pp. 355-358. https://doi.org/10.1007/s10009-018-0494-5 with implementation in Dutch construction, Journal of Management in Engineering 34 (6) (2018). https://doi.org/10.1061/(ASCE)ME.1943-5479.0000644

1035 [60] B. Dave, A. Buda, A. Nurminen, K. Främling, A framework for integrating BIM and 1036 IoT through open standards, Automation in Construction 95 (2018) pp. 35-45, 1037 https://doi.org/10.1016/j.autcon.2018.07.022

1038 [61] A. Grilo, R. Jardim-Goncalves, Value proposition on interoperability of BIM and collaborative working environments, Automation in Construction 19 (5) (2010) pp. 522-530. https://doi.org/10.1016/j.autcon.2009.11.003

[62] F.H. Abanda, C. Vidalakis, A.H. Oti, J.H.M. Tah, A critical analysis of Building Information Modelling systems used in construction projects, Advances in Engineering Software 90 (2015) pp. 183-201. https://doi.org/10.1016/j.advengsoft.2015.08.009

1044 [63] K. Kensek, BIM guidelines inform facilities management databases: A case study 1045 over time, Buildings 5 (3) (2015) pp. 899-916. https://doi.org/10.3390/buildings5030899

1046 [64] C. Kropp, C. Koch, M. König, Interior construction state recognition with 4D BIM 1047 registered image sequences, Automation in Construction 86 (2018) pp. 11-32. https://doi.org/10.1016/j.autcon.2017.10.027

[65] A. Mirzaei, F. Nasirzadeh, M. Parchami Jalal, Y. Zamani, 4D-BIM dynamic timespace conflict detection and quantification system for building construction projects, Journal of Construction Engineering and Management 144 (7) (2018). https://doi.org/10.1061/(ASCE)CO.1943-7862.0001504

[66] K.K. Han, M. Golparvar-Fard, Appearance-based material classification for monitoring of operation-level construction progress using 4D BIM and site photologs, 
Automation in Construction 53 (2015) pp. 44-57 .

https://doi.org/10.1016/j.autcon.2015.02.007

[67] I. Chan, A. Liu, B. Chen, Management strategies for 5D-BIM adoption in Hong Kong, Proceedings of the 21st International Symposium on Advancement of Construction Management and Real Estate, Springer, 2018, pp. 1023-1039. https://doi.org/10.1007/978981-10-6190-5 91

[68] R. Stanley, D. Thurnell, The benefits of, and barriers to, implementation of 5D BIM for quantity surveying in New Zealand, Australasian journal of construction economics and building 14 (1) (2014) pp. 105-117. https://doi.org/10.5130/AJCEB.v14i1.3786

[69] R. Davies, C. Harty, Measurement and exploration of individual beliefs about the consequences of building information modelling use, Construction Management and Economics 31 (11) (2013) pp. 1110-1127. https://doi.org/10.1080/01446193.2013.848994

[70] T. Hartmann, H. Van Meerveld, N. Vossebeld, A. Adriaanse, Aligning building information model tools and construction management methods, Automation in Construction 22 (2012) pp. 605-613. https://doi.org/10.1016/j.autcon.2011.12.011

[71] B.J. Gledson, D. Greenwood, The adoption of 4D BIM in the UK construction industry: An innovation diffusion approach, Engineering, Construction and Architectural Management 24 (6) (2017) pp. 950-967. https://doi.org/10.1108/ECAM-03-2016-0066

[72] A. Perianes-Rodriguez, L. Waltman, N.J. van Eck, Constructing bibliometric networks: A comparison between full and fractional counting, Journal of Informetrics 10 (4) (2016) pp. 1178-1195. https://doi.org/10.1016/j.joi.2016.10.006

[73] C.S. Park, D.Y. Lee, O.S. Kwon, X. Wang, A framework for proactive construction defect management using BIM, augmented reality and ontology-based data collection template, Automation in Construction 33 (2013) pp. 61-71. https://doi.org/10.1016/j.autcon.2012.09.010

[74] H.L. Chi, S.C. Kang, X. Wang, Research trends and opportunities of augmented reality applications in architecture, engineering, and construction, Automation in Construction 33 (2013) pp. 116-122. https://doi.org/10.1016/j.autcon.2012.12.017

[75] X. Wang, M.J. Kim, P.E.D. Love, S.C. Kang, Augmented reality in built environment: Classification and implications for future research, Automation in Construction 32 (2013) pp. 1-13. https://doi.org/10.1016/j.autcon.2012.11.021

[76] X. Wang, P.E.D. Love, M.J. Kim, C.-S. Park, C.-P. Sing, L. Hou, A conceptual framework for integrating Building Information Modeling with Augmented Reality, Automation in Construction 34 (0) (2013) pp. 37-44.

https://doi.org/10.1016/j.autcon.2012.10.012

[77] W. Shou, J. Wang, X. Wang, H.Y. Chong, A comparative review of building information modelling implementation in building and infrastructure industries, Archives of Computational Methods in Engineering 22 (2) (2015) pp. 291-308. https://doi.org/10.1007/s11831-014-9125-9

[78] M. Laakso, A. Kiviniemi, The IFC standard: A review of history, development, and standardization, Electronic Journal of Information Technology in Construction 17 (2012) pp. 134-161, ISSN: 1874-4753. URI: http://usir.salford.ac.uk/id/eprint/28373

[79] H. Bae, M. Golparvar-Fard, J. White, High-precision vision-based mobile augmented reality system for context-aware architectural, engineering, construction and facility management (AEC/FM) applications, Visualization in Engineering 1 (1) (2013). https://doi.org/10.1186/2213-7459-1-3

[80] X. Zhang, Green real estate development in China: State of art and prospect agenda-A review, Renewable and Sustainable Energy Reviews 47 (2015) pp. 1-13. https://doi.org/10.1016/j.rser.2015.03.012

[81] Y. Jiao, S. Zhang, Y. Li, Y. Wang, B. Yang, Towards cloud Augmented Reality for 
construction application by BIM and SNS integration, Automation in Construction 33 (2013) pp. 37-47. https://doi.org/10.1016/j.autcon.2012.09.018

[82] Z. Ding, J. Zuo, J. Wu, J. Wang, Key factors for the BIM adoption by architects: A China study, Engineering, Construction and Architectural Management 22 (6) (2015) pp. 732-748. https://doi.org/10.1108/ECAM-04-2015-0053

[83] X. Wang, P.E.D. Love, M.J. Kim, W. Wang, Mutual awareness in collaborative design: An Augmented Reality integrated telepresence system, Computers in Industry 65 (2) (2014) pp. 314-324. https://doi.org/10.1016/j.compind.2013.11.012

[84] J. Irizarry, M. Gheisari, G. Williams, K. Roper, Ambient intelligence environments for accessing building information: A healthcare facility management scenario, Facilities 32 (3) (2014) pp. 120-138. https://doi.org/10.1108/F-05-2012-0034

[85] S. Lee, S. Tae, S. Roh, T. Kim, Green template for life cycle assessment of buildings based on building information modeling: Focus on embodied environmental impact, Sustainability (Switzerland) 7 (12) (2015) pp. 16498-16512.

https://doi.org/10.3390/su71215830

[86] L. Hou, X. Wang, M. Truijens, Using augmented reality to facilitate piping assembly: An experiment-based evaluation, Journal of Computing in Civil Engineering 29 (1) (2015). https://doi.org/10.1061/(ASCE)CP.1943-5487.0000344

[87] K.C. Yeh, M.H. Tsai, S.C. Kang, On-site building information retrieval by using projection-based augmented reality, Journal of Computing in Civil Engineering 26 (3) (2012) pp. 342-355. https://doi.org/10.1061/(ASCE)CP.1943-5487.0000156

[88] S. Rankohi, L. Waugh, Review and analysis of augmented reality literature for construction industry, Visualization in Engineering 1 (1) (2013).

https://doi.org/10.1186/2213-7459-1-9

[89] S. Yue, M. Chen, Y. Wen, G. Lu, Service-oriented model-encapsulation strategy for sharing and integrating heterogeneous geo-analysis models in an open web environment, ISPRS Journal of Photogrammetry and Remote Sensing 114 (2016) pp. 258-273. https://doi.org/10.1016/j.isprsjprs.2015.11.002

[90] B. Esmaeili, M.R. Hallowell, Diffusion of safety innovations in the construction industry, Journal of Construction Engineering and Management 138 (8) (2012) pp. 955-963. https://doi.org/10.1061/(ASCE)CO.1943-7862.0000499

[91] M. Gheisari, J. Irizarry, Investigating human and technological requirements for successful implementation of a BIM-based mobile augmented reality environment in facility management practices, Facilities 34 (1-2) (2016) pp. 69-84. https://doi.org/10.1108/F-04$\underline{2014-0040}$

[92] G. Williams, M. Gheisari, P.J. Chen, J. Irizarry, BIM2MAR: An efficient BIM translation to mobile augmented reality applications, Journal of Management in Engineering 31 (1) (2014). https://doi.org/10.1061/(ASCE)ME.1943-5479.0000315

[93] C.R. Ahn, S. Lee, F. Peña-Mora, Application of low-cost accelerometers for measuring the operational efficiency of a construction equipment fleet, Journal of Computing in Civil Engineering 29 (2) (2015). https://doi.org/10.1061/(ASCE)CP.1943-5487.0000337

[94] A. Shirazi, A.H. Behzadan, Content delivery using augmented reality to enhance students' performance in a building design and assembly project, Advances in Engineering Education 4 (3) (2015). ISSN: EISSN-1941-1766

[95] X. Wang, P.S. Dunston, Tangible mixed reality for remote design review: a study understanding user perception and acceptance, Visualization in Engineering 1 (1) (2013). https://doi.org/10.1186/2213-7459-1-8

[96] M. Chu, J. Matthews, P.E.D. Love, Integrating mobile Building Information Modelling and Augmented Reality systems: An experimental study, Automation in Construction 85 (2018) pp. 305-316. https://doi.org/10.1016/j.autcon.2017.10.032 

(2018) pp. 176-189. https://doi.org/10.1016/j.autcon.2017.10.005

[98] E.M. Rogers, Diffusion of Innovations, 4th ed., Free Press., New York, 1995. ISBN1159 10: 0029266718.

1160 [99] E. Kamel, A.M. Memari, Review of BIM's application in energy simulation: Tools, issues, and solutions, Automation in Construction 97 (2019) pp. 164-180. https://doi.org/10.1016/j.autcon.2018.11.008

[100] S.M. Sepasgozar, S.R. Davis, H. Li, X. Luo, Modeling the implementation process for new construction technologies: thematic analysis based on Australian and US practices, Journal of Management in Engineering 34

4 (3)

(2018).

1166 https://doi.org/10.1061/(ASCE)ME.1943-5479.0000608

1167 [101] S.M. Sepasgozar, S.R. Davis, M. Loosemore, Dissemination practices of construction sites' technology vendors in technology exhibitions, Journal of Management in Engineering 34 (6) (2018). https://doi.org/10.1061/(ASCE)ME.1943-5479.0000650

[102] C. Gutwin, S. Greenberg, A descriptive framework of workspace awareness for realtime groupware, Computer Supported Cooperative Work (CSCW) 11 (3) (2002) pp. 411-446. https://doi.org/10.1023/A:1021271517844

[103] M. Haoues, A. Sellami, H. Ben-Abdallah, L. Cheikhi, A guideline for software architecture selection based on ISO 25010 quality related characteristics, International Journal of Systems Assurance Engineering and Management 8 (2017) pp. 886-909. https://doi.org/10.1007/s13198-016-0546-8

[104] S. Xu, K. Liu, L.C.M. Tang, W. Li, A framework for integrating syntax, semantics and pragmatics for computer-aided professional practice: With application of costing in construction industry, Computers in Industry 83 (2016) pp. 28-45. https://doi.org/10.1016/j.compind.2016.08.004 [105] C. Fernández-Caramés, F.J. Serrano, V. Moreno, B. Curto, J.F. Rodríguez-Aragón, R. Alves, A real-time indoor localization approach integrated with a Geographic Information System (GIS), Robotics and Autonomous Systems 75 (2016) pp. 475-489. https://doi.org/10.1016/j.robot.2015.08.005

1185 [106] U. Isikdag, J. Underwood, G. Aouad, An investigation into the applicability of building information models in geospatial environment in support of site selection and fire response management processes, Advanced Engineering Informatics 22 (4) (2008) pp. 504519. https://doi.org/10.1016/j.aei.2008.06.001

1189 [107] P.-C. Lee, Y. Wang, T.-P. Lo, D. Long, An integrated system framework of building information modelling and geographical information system for utility tunnel maintenance management, Tunnelling and Underground Space Technology 79 (2018) pp. 263-273. https://doi.org/10.1016/j.tust.2018.05.010

[108] L.-C. Chen, C.-H. Wu, T.-S. Shen, C.-C. Chou, The application of geometric network models and building information models in geospatial environments for fire-fighting simulations, Computers, Environment and Urban Systems 45 (2014) pp. 1-12. https://doi.org/10.1016/j.compenvurbsys.2014.01.003

1197 [109] C.T. Lu, R.F. Dos Santos, L.N. Sripada, Y. Kou, Advances in GML for geospatial applications, Geoinformatica 11 (1) (2007) pp. 131-157. https://doi.org/10.1007/s10707-006$\underline{0013-9}$

1200 [110] J. Farooq, P. Sharma, R. Sreerama Kumar, Applications of building information modeling in electrical systems design, Journal of Engineering Science and Technology Review 10 (6) (2017) pp. 119-128. https://doi.org/10.25103/jestr.106.16 [111] J. Park, D. Ahn, J. Lee, Development of data fusion method based on topological relationships using IndoorGML core module, Journal of Sensors 2018 (2018). 
1206 [112] S. Noor, L. Shah, M. Adil, N. Gohar, G.E. Saman, S. Jamil, F. Qayum, Modeling and 1207 representation of built cultural heritage data using semantic web technologies and building 1208 information model, Computational and Mathematical Organization Theory (2018). https://doi.org/10.1007/s10588-018-09285-y

1210 [113] S. Vilgertshofer, A. Borrmann, Using graph rewriting methods for the semi-automatic generation of parametric infrastructure models, Advanced Engineering Informatics 33 (2017) pp. 502-515. https://doi.org/10.1016/j.aei.2017.07.003

[114] A. Borrmann, T.H. Kolbe, A. Donaubauer, H. Steuer, J.R. Jubierre, M. Flurl, Multiscale geometric-semantic modeling of shield tunnels for GIS and BIM applications, Computer-Aided Civil and Infrastructure Engineering 30 (4) (2015) pp. 263-281. https://doi.org/10.1111/mice. 12090

1217 [115] N.O. Sönmez, A review of the use of examples for automating architectural design tasks, CAD Computer Aided Design 96 (2018) pp. 13-30.

https://doi.org/10.1016/j.cad.2017.10.005

[116] J. Du, Z. Zou, Y. Shi, D. Zhao, Zero latency: Real-time synchronization of BIM data in virtual reality for collaborative decision-making, Automation in Construction 85 (2018) pp. 51-64. https://doi.org/10.1016/j.autcon.2017.10.009

[117] A. Costin, C. Eastman, Need for Interoperability to enable seamless information exchanges in smart and sustainable urban systems, Journal of Computing in Civil Engineering 33 (3) (2019), https://doi.org/10.1061/(ASCE)CP.1943-5487.0000824

[118] A.L.C. Ciribini, S. Mastrolembo Ventura, M. Paneroni, Implementation of an interoperable process to optimise design and construction phases of a residential building: A BIM Pilot Project, Automation in Construction 71 (2016) pp. 62-73. https://doi.org/10.1016/j.autcon.2016.03.005 existing buildings: Literature review and future needs, Automation in Construction 38 (0) (2014) pp. 109-127. https://doi.org/10.1016/j.autcon.2013.10.023

[120] Y. Arayici, T. Fernando, V. Munoz, M. Bassanino, Interoperability specification development for integrated BIM use in performance based design, Automation in Construction 85 (2018) pp. 167-181. https://doi.org/10.1016/j.autcon.2017.10.018 [121] P.-H. Chen, T.C. Nguyen, A BIM-WMS integrated decision support tool for supply chain management in construction, Automation in Construction 98 (2019) pp. 289-301. https://doi.org/10.1016/j.autcon.2018.11.019

[122] L.M. Khodeir, A.A. Nessim, BIM2BEM integrated approach: Examining status of the adoption of building information modelling and building energy models in Egyptian architectural firms, Ain Shams Engineering Journal 9 (4) (2018) pp. 1781-1790. https://doi.org/10.1016/j.asej.2017.01.004 information modelling (BIM) uses for the oil and gas projects, Archives of Computational Methods in Engineering 25 (2) (2018) pp. 349-396. https://doi.org/10.1007/s11831-0169201-4

1247 [124] J.B. Kim, W. Jeong, M.J. Clayton, J.S. Haberl, W. Yan, Developing a physical BIM library for building thermal energy simulation, Automation in Construction 50 (2015) pp. 1628. https://doi.org/10.1016/j.autcon.2014.10.011 and its interoperability through the building information modeling (BIM) platform, Buildings 3 (2) (2013). https://doi.org/10.3390/buildings3020380 conventional wall components based on a parametric-integrated design, Automation in 
1255 Construction 110 (2020). https://doi.org/10.1016/j.autcon.2019.103005

1256 [127] O. Davtalab, A. Kazemian, B. Khoshnevis, Perspectives on a BIM-integrated software 1257 platform for robotic construction through Contour Crafting, Automation in Construction 89 1258 (2018) pp. 13-23. https://doi.org/10.1016/j.autcon.2018.01.006

1259 [128] D. Mzyece, I.E. Ndekugri, N.A. Ankrah, Building information modelling (BIM) and 1260 the CDM regulations interoperability framework, Engineering, Construction and 1261 Architectural Management (2019). https://doi.org/10.1108/ECAM-10-2018-0429

1262 [129] E.P. Karan, J. Irizarry, Extending BIM interoperability to preconstruction operations 1263 using geospatial analyses and semantic web services, Automation in Construction 53 (2015) 1264 pp. 1-12. https://doi.org/10.1016/j.autcon.2015.02.012

1265 [130] J. Wu, J. Zhang, New automated BIM object classification method to support BIM 1266 interoperability, Journal of Computing in Civil Engineering 33 (5) (2019). 1267 https://doi.org/10.1061/(ASCE)CP.1943-5487.0000858

1268 [131] E. Trunzer, A. Calà, P. Leitão, M. Gepp, J. Kinghorst, A. Lüder, H. Schauerte, M.

1269 Reifferscheid, B. Vogel-Heuser, System architectures for Industrie 4.0 applications,

1270 Production Engineering 13 (3) (2019) pp. 247-257. https://doi.org/10.1007/s11740-019-

$1271 \quad \underline{00902-6}$ 